\title{
Electrode Potentials in Fused Systems X. Measurement of Cation Concentration in Molten Salts Using Glass Membrane Electrodes
}

\author{
Kurt H. Stern and Susan E. Meador
}

(June 30, 1965)

\begin{abstract}
A potentiometric method utilizing glass membrane reference electrodes in a concentration cell for the continuous measurement in situ of molten salt composition is presented. Relevant data for the AgCl-NaCl, $\mathrm{AgBr}-\mathrm{NaBr}$, and $\mathrm{Ag}_{2} \mathrm{SO}_{4}-\mathrm{Na}_{2} \mathrm{SO}_{4}$ systems are given. Using cells of the type
\end{abstract}

$$
M_{1}\left|M_{1} A\left(a_{R}\right), M_{2} A\left(a_{R}^{\prime}\right)\right| \text { glass }\left|M_{1} A\left(a_{2}\right), M_{2} A\left(a_{2}^{\prime}\right)\right| M_{1}
$$

where the $a$ 's are activities, the unknown mole fraction $X_{2}$ can be calculated from the equation

$$
\log \left(\frac{X_{2}}{1-X_{2}}\right)=\frac{E}{2.303(R T / F) t^{\prime}}-\log \left(\frac{1-X_{R}}{X_{R}}\right)
$$

\begin{abstract}
where $t^{\prime}$ is a concentration-independent constant of the system and $X_{R}$ is the concentration of $M_{1} A$ in the reference electrode. The method is capable of measuring $X_{2}$ in molten salt with an accuracy of better than 5 percent over a concentration range of $10^{4}$. Application of the method to cations other than silver is discussed.
\end{abstract}

Key Words: Analysis, electrodes, glass, membranes, metal ions, molten salts, membrane electrodes.

\section{Introduction}

Increasing need for reliable reference electrodes in molten salts has led, in recent years, to the development of glass membrane electrodes for use in these media. These electrodes have a number of advantages over electrodes in which a liquid junction is maintained by means of pinholes, asbestos fibers, frits, etc., between the reference and indicator compartments of the cell. They are easily constructed, rugged, and maintain constant potential over relatively long periods of time.

A number of membrane electrode designs, all based on the $\mathrm{Ag}-\mathrm{Ag}^{+}$equilibrium, have been published $[1,2,3,4] .^{1}$ In contrast to aqueous systems in which the glass electrode functions as indicator electrode, primarily for $p \mathrm{H}$ measurements, in molten salts it serves as a reference electrode with respect to which potential changes at other electrodes can be observed. For this application the primary requirement is stability and reproducibility, i.e., several electrodes of identical design should vary as little as possible in potential behavior. To be useful in this sense it is not necessary that the potential of such an electrode be known on any thermodynamic scale, e.g., with respect to the $1 / 2 \mathrm{Cl}_{2}(\mathrm{~g})+e=\mathrm{Cl}^{-}$equilibrium of the chlorine electrode.

\footnotetext{
${ }^{1}$ Figures in brackets indicate the literature references at the end of this paper.
}

It is by now well known that when a glass electrode is combined with another electrode, either in a concentration or in a chemical cell, the measured emf will differ markedly from the Nernst value except in the special case in which the compositions on both sides of the glass are nearly identical [1]. The reason for this deviation lies in the selectivity of every glass for certain ions in the melt. Thus the ionic transport through the glass is relatively independent of melt composition; this leads to a membrane potential which must be taken into account, in addition to the Nernst value.

We have recently studied the behavior of glass in a variety of molten salt media in order to gain more information on ionic transport in glass $[5,6,7,8]$. One result of this work is that it is now possible to use glass membrane reference electrodes for the determination of melt composition with respect to certain ions. Using these electrodes the melt composition can be measured continuously without disturbing the system by sampling. The purpose of the present paper is to give a more detailed discussion of those aspects of glass electrodes which pertain to the measurement of melt composition, particularly in the dilute range. We have illustrated this by new measurements of the $\mathrm{AgCl}-\mathrm{NaCl}$ and $\mathrm{AgBr}-\mathrm{NaBr}$ systems which were previously measured at higher silver concentrations, and of the $\mathrm{Ag}_{2} \mathrm{SO}_{4}-\mathrm{Na}_{2} \mathrm{SO}_{4}$ system which has not previously been studied. 
We begin by discussing a simple concentration cell

$$
M_{1}\left|M_{1} A\left(a_{1}\right), M_{2} A\left(a_{1}^{\prime}\right)\right| \text { glass }\left|M_{1} A\left(a_{2}\right), M_{2} A\left(a_{2}^{\prime}\right)\right| M_{1}
$$

where the $a$ 's represent activities on the mole fraction scale. As shown previously the emf of this cell is

$$
E_{\text {cell }}=(R T / F)\left[\ln a_{2} / a_{1}-\int_{a_{1}}^{a_{2}} \sum_{i} t_{i} d \ln a_{i}\right]
$$

which is formally also the potential of the cell with liquid junction. The chief difference between membrane and liquid junction potentials is that in the former case (a) only ions transported across the glass are included in the summation, and (b) if the melt contains more than 2 percent sodium, $t_{i}$ is a constant in any cell and can be taken outside the integral [5]. For systems containing a single anion only cation terms are included in the summation. Since $\Sigma t_{i}=1$, eq (1) becomes

$$
E_{\text {cell }}=(R T / F) t_{M_{2}^{+}} \ln \left[\left(a_{2} / a_{1}\right)\left(a_{1}^{\prime} / a_{2}^{\prime}\right)\right] .
$$

Equation (2) is useful for the measurement of an unknown composition only if (a) $t_{M_{2}^{+}}$is really independent of composition over the entire concentration range, (b) no changes occur in the reference electrode, e.g. composition changes by vaporization, and (c) the thermodynamic behavior of the melt, i.e., the activity coefficients of the components, are known. In a study of several silver halide-alkali halide solutions [5] it was found that (a) is satisfied if the melt contains at least 2 percent sodium, but not if it contains only the larger alkali metal cations. Condition (b) can be satisfied fairly well by using small diameter tubing. For the purpose of measuring melt composition condition (c) imposes a great inconvenience. In that case it is probably preferable to write eq (2) in terms of the mole fractions and to let $t_{M_{2}^{+}}$absorb the nonideality of the system. Although this treatment can give misleading results if precise information on ion transport in glass is desired [7], it is justified when the purpose of the measurement is the determination of melt composition. In that case it is more convenient to write eq (2) in terms of the mole fraction, viz

$$
E_{\text {cell }}=(R T / F) t^{\prime} \ln \left[\left(X_{2} / X_{1}\right)\left(X_{1}^{\prime} / X_{2}^{\prime}\right)\right]
$$

where

$$
t^{\prime}=t_{M_{2}^{+}}\left\{1+\frac{\ln \left[\left(\frac{\gamma_{2}}{\gamma_{1}}\right)\left(\frac{\gamma_{1}^{\prime}}{\gamma_{2}^{\prime}}\right)\right]}{\ln \left[\left(\frac{X_{2}}{X_{1}}\right)\left(\frac{X_{1}^{\prime}}{X_{2}^{\prime}}\right)\right]}\right\}
$$

and the $\gamma$ 's are the Raoult's law activity coefficients of the components. Making use of $X_{1}+X_{1}^{\prime}=X_{2}$
$+X_{2}^{\prime}=1$ gives

$$
E_{\text {cell }}=(R T / F) t^{\prime} \ln \left[\left(X_{2} / X_{1}\right)\left(1-X_{1}\right) /\left(1-X_{2}\right)\right]
$$

$t^{\prime}$ can then be regarded as the empirical slope obtained in a calibration run when $E_{\text {cell }}$ is plotted against $(R T / F) \ln \left[\left(X_{2} / X_{1}\right)\left(1-X_{1}\right) /\left(1-X_{2}\right)\right]$. In practice, it is most convenient to keep one side fixed as a reference and to vary the composition of the other side. Once $t^{\prime}$ has been determined for a particular melt and glass it can then be used in eq (5) to determine unknown concentrations in this system. For example if $X_{1}=X_{R}$, the reference composition, eq (5) can be written

$$
\log \left(\frac{X_{2}}{1-X_{2}}\right)=\frac{E}{2.303(R T / F) t^{\prime}}-\log \left(\frac{1-X_{R}}{X_{R}}\right) .
$$

For dilute melts $1-X_{2} \simeq 1$.

\section{Experimental Part}

The general procedure has been outlined previously [4]. Some changes and refinements are discussed below. All experiments were carried out in alumina crucibles open to the atmosphere to duplicate more probable conditions of use.

\subsection{Reference Electrodes}

Preparation and pretreatment of the glass tubes and silver wire have been described [4]. The reference melt was prepared by melting appropriate quantities of the silver and sodium salts to give $\sim 10$ mole percent silver. This concentration appears to be suitable for both higher and lower unknown concentrations and minimizes the corrosion of the silver wire [8]. It proved most useful to make up 50 to $100 \mathrm{~g}$ of this composition at one time and then use 2 to $3 \mathrm{~g}$ of it in each electrode. Since microcrystalline segregation occurs in these melts on cooling (see below) the quenched melt was ground to a fine powder before use. Several representative portions were analyzed by electrodeposition. The precision of the analytical method was better than 1 percent.

\subsection{General Procedure}

Two identically prepared reference electrodes were placed in an alumina crucible containing $\sim 120 \mathrm{~g}$ of the sodium salt and heated to the desired temperature. Weighed amounts of the corresponding silver salt were added. Emf's were measured between a 30 mil bare silver wire in the melt and each of the reference electrodes, as well as between the two reference electrodes, using a Leeds and Northrup K-3 potentiometer and electronic galvanometer. The melt, open to the atmosphere, was continually stirred with a stream of dried helium passing through a 4-hole ceramic tube.

In unstirred or insufficiently stirred melts the emf 
was always lower, indicating that a layer of higher silver ion concentration surrounds the indicator electrode. The effect is most pronounced in dilute solution and decreases with rising concentration. With increasing stirring rate the emf increases to a limiting value. We assume that this emf then corresponds to that for the bulk melt.

In our initial experiments samples of the melts were taken by dipping a cold ceramic rod and quickly withdrawing it. Analyses of the samples frozen on the rod gave increasingly lower concentrations of silver than the values calculated with a constant transport number as the total silver concentration increased. In other words, if the analytical values are used to calculate transport numbers, these latter decrease markedly as the silver content of the melt rises. These observations are explicable in terms of the phase diagrams of various silver-alkali salts published by Zemczuzny [9]. He showed that in these systems the solid phase is always poorer in silver than the liquid in equilibrium with it. The difference increases with rising silver concentration. Apparently then, the liquid composition cannot be frozen into the solid even by rapid quenching. Consequently, samples for analysis were obtained by dipping a $2 \mathrm{ml}$ platinum bucket attached to a long heavy platinum wire into the melt, equilibrating its temperature with the melt, withdrawing samples and pouring these as rapidly as possible onto a heavy metal tray. This procedure was repeated as many times as necessary to obtain a sufficient sample for analysis. Alternatively, samples were piped into a $9 \mathrm{~mm}$ wide fused silica tube equilibrated with the melt and poured into the tray. Samples were taken after the emf had been steady for at least 15 to $20 \mathrm{~min}$. The temperature was measured with a chromel-alumel thermocouple which was placed into a glass tube immersed directly in the melt. Temperatures are estimated to be accurate to within $\pm 1^{\circ}$.

\subsection{Sources of Error}

\section{a. Stability and Reproducibility of Reference Electrodes}

No extensive stability tests were carried out. However, we found that some electrodes kept in the melts in the 800 to $900{ }^{\circ} \mathrm{C}$ range for more than 8 to $10 \mathrm{hr}$ began to deviate increasingly from newly immersed electrodes. This effect appears to be greater in the halides than in the sulfate. Since these electrodes are so easily and cheaply constructed we regard them as the "throw-away" type and suggest replacing them every 8 to $10 \mathrm{hr}$.

The potential between identically prepared reference electrodes immersed in the same melt varies randomly, but never exceeds $2 \mathrm{mV}$, this larger difference occurring in the sulfate system. In the halides the difference was usually a few tenths $\mathrm{mV}$. For the determination of actual concentrations the limit of useful measurement is $\sim 1 \mathrm{mV}$; for relative measure- ments of concentration ratios or rates of change, e.g., in kinetic studies [8], measurements are significant to $\sim 0.1 \mathrm{mV}$.

\section{b. Indicator Electrode Errors}

The lower limit of measurable silver ion concentration is imposed by the nearly instantaneous corrosion of the indicator electrode in alkali metal salts. Thus, if an emf is measured between the reference and a bare silver wire in a pure alkali metal salt the calculated silver ion concentration is never lower than $10^{-5}$ [8]. This is presumably the concentration near the metal surface and not bulk melt composition.

Concentration gradients which build up near the electrode in dilute solution in unstirred melts require good stirring if the bulk composition is to be measured, the difference in emf of stirred and unstirred melts, can easily amount to $20 \mathrm{mV}$.

As the melt composition approaches that of the reference the emf decreases to zero. It is clear from eq (6) that the accuracy of the measurement must also decrease due to loss of significant figures from $E$ since the uncertainty of the measurement remains fairly constant. It is thus advisable to use a reference composition which differs sufficiently from the melt to be measured to give an emf of $\sim 0.1 \mathrm{~V}$.

We illustrate the effect of several errors by calculating the consequence of these on the measured concentration. Since these errors differ somewhat for high and low concentrations, one example of each is given.

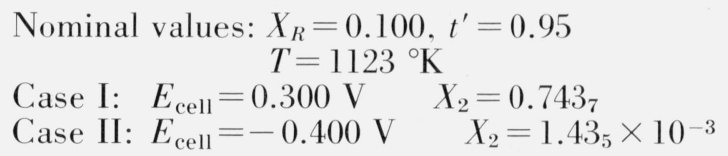

\begin{tabular}{c|c|c|c|c}
\hline \hline Error & $X(\mathrm{I})$ & $\Delta X(\mathrm{I})$ & $X(\mathrm{II}) \times 10^{3}$ & $\Delta X(\mathrm{II}) \times 10^{3}$ \\
\hline$\Delta t^{\prime}=0.01$ & & & & \\
$\Delta X_{R}=.001$ & $0.739_{6}$ & $0.004_{1}$ & $1.47_{3}$ & $0.03_{8}$ \\
$\Delta E=.001$ & $.745_{7}$ & $.002_{0}$ & $1.45_{1}$ & $.01_{6}$ \\
$\Delta T=2^{0}$ &. $.002_{0}$ & $1.42_{0}$ & $.01_{5}$ \\
\hline
\end{tabular}

On the basis of the above calculation the accuracy of the method is estimated to be approximately 1 percent for fairly concentrated solutions, and 5 percent for dilute $\left(10^{-4}<X_{2}<10^{-2}\right)$ ones. Since the major source of error results from uncertainties in $t^{\prime}$ it is important that the calibration run be carried out carefully. In particular, the melt compositions in the calibration must be accurately known. The required accuracy can be obtained by careful weighing of the components for silver-rich melts; for melts dilute in silver it is important that a representative sample of the liquid composition is obtained for analysis (see above). 


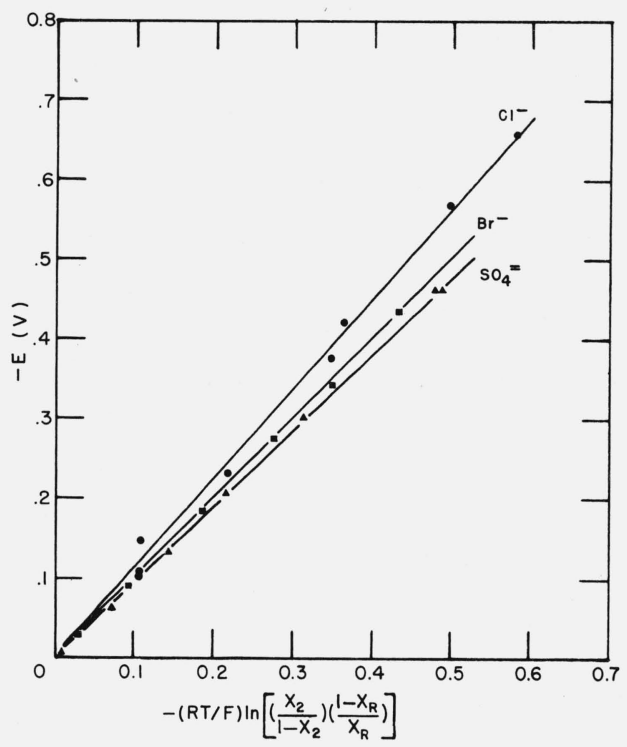

Figure 1. Plot of eq (5).

$X_{1}=X_{R}$ for three $\mathrm{Ag}^{+} \cdot \mathrm{Na}^{+}$systems and $\mathrm{Vycor}$ glass membranes. The anions are shown to the right of the respective curves.

\section{Results}

Plots of eq (5) for the three systems of this study are shown in figure 1 . The origin of course represents $X_{1}=X_{2} \simeq 0.1$. (Slightly different reference compositions were used in the three systems.) The fact that all three plots pass through the origin shows that asymmetry potentials are absent. The range of concentration represented by the plots is $10^{-4}<X_{2}<10^{-1}$. For each of the three systems the plot is linear, i.e., $t^{\prime}$ is constant over this range. The small differences in the slopes probably arise from differences in the activity coefficient terms. Combined with the data of previous studies [4,5], these results show that the method presented in this paper is capable of measuring the silver ion concentration in $\mathrm{Ag}^{+}-\mathrm{Na}^{+}$melts over a range of $10^{4}$. The values of $t^{\prime}$ and its standard deviation for the systems studied are

\begin{tabular}{l|c|c}
\hline \hline & $t^{\prime}$ & $\sigma$ \\
\cline { 2 - 3 } & & \\
$\mathrm{AgCl}-\mathrm{NaCl}$ & 1.148 & 0.0034 \\
$\mathrm{AgBr}-\mathrm{NaBr}$ & 1.009 & .008 \\
$\mathrm{Ag}_{2} \mathrm{SO}_{4}-\mathrm{Na}_{2} \mathrm{SO}_{4}$ & 0.965 & .011 \\
\hline
\end{tabular}

$t^{\prime}$ is independent of temperature between 800 and 900 ${ }^{\circ} \mathrm{C}$ [4]. A previous comparison between Vycor and Supremax [2, 4], two glasses of quite different composition, indicates that $t^{\prime}$ is nearly independent of the particular glass used.

\section{Conclusions}

A potentiometric method has been presented which utilizes glass membrane reference electrodes in a concentration cell arrangement for the continuous measurement of molten salt composition in situ with respect to certain ions.

The method was illustrated by measurements of three melts containing silver and sodium ions. However, the principles which are involved are applicable to other ions as well. For example, data on the CuCl$\mathrm{NaCl}$ system have already been obtained [7]. Thus it should be possible to measure the concentration of any metal ion for which a reversible electrode can be constructed. At present the method appears to be limited to melts containing at least 2 mole percent sodium ion. Another limitation of the method is that the formation of insoluble oxides on and any appreciable corrosion of the metal wires used in the reference and indicator electrodes must be avoided. In some cases this may require an inert atmosphere over the measurement part of the system. In studying any particular system the applicability of the method must be tested and a calibration curve of the type shown in figure 1 constructed.

\section{References}

[1] J. O'M. Bockris, G. J. Hills, D. Inman, and L. Young, J. Sci. Instr. 33, 438 (1956).

[2] R. Littlewood, Electrochim. Acta. 3, 270 (1961).

[3] G. Danner and M. Rey, Electrochim. Acta. 4, 274 (1961).

[4] K. H. Stern, J. Phys. Chem. 67, 893 (1963).

[5] K. H. Stern and J. L. Stiff. J. Electrochem. Soc. 111,893 (1964).

[6] K. H. Stern, J. Electrochem. Soc. 111, 208 (1965).

[7] K. H. Stern and S. E. Meador, unpublished results.

[8] K. H. Stern and W. E. Reid, Jr., J. Phys. Chem. 68, 3757 (1964).

[9] S. F. Zemczuzny, Z. anorg. u. allgem. Chem. 153, 47 (1926).

(Paper 69A6-379) 


\section{Publications of the National Bureau of Standards*}

\section{Selected Abstracts}

\begin{abstract}
Determination of the composition of complexes and their instability constant by calorimetry, I. The cuprocyanide complexes, A. Brenner, J. Electrochem. Soc. 112 , No. 6, 611621 (June 1965).

The calorimetric method for determining the chemical formula and the instability constant of a complex ion involves the determination of the partial molal heat effects resulting from the separate addition of increments of each of the constituents of the complex to a complete range of mixtures of the constituents. The general mathematical derivations necessary for the utilization of the method have been developed, and the complex copper cyanides have been used as an example. The instability constants for the $\mathrm{Cu}(\mathrm{CN})_{3}^{--}$ and the $\mathrm{Cu}(\mathrm{CN})^{---}$ions were found to be $1.0 \times 10^{-5}$ and $2.3 \times 10^{-3}$ respectively.
\end{abstract}

Mass spectrum of yttrium chloride vapor, J. D. McKinley J. Chem. Phys. 42, No. 6, 2245-2246 (Mar. 15, 1965).

The mass spectrum of vapor in equilibrium with anhydroús yttrium chloride was examined by a Knudsen effusion technique between $800^{\circ}$ and $1000^{\circ} \mathrm{K}$. Ions due to monomeric and dimeric vapor molecules were identified. Heats of evaporation and sublimation for the two species are: dimer $\mathrm{H}_{a}=86 \mathrm{kcal} / \mathrm{mol}, \mathrm{H}=74 \mathrm{kcal} / \mathrm{mol}$ monomer $\mathrm{H}_{s}=57 \mathrm{kcal} / \mathrm{mol}, \mathrm{H}=47 \mathrm{kcal} / \mathrm{mol}$.

Method of adjusting force constants and its application to $\mathrm{H}_{2} \mathrm{O}, \mathrm{H}_{2} \mathrm{CO}, \mathrm{CH}_{2} \mathrm{Cl}$ and their deuterated molecules. T. Shimanouchi and I. Suzuki, J. Chem. Phys. 42, No. 1, 296-308 (Jan. 1, 1965).

A new method for the adjustment of vibrational force constants is presented. It avoids some of the divergence difficulties which may be encountered in perturbation and least-squares procedures. The new method employs an efficient computer program to adjust an initial set of force constants in accordance with the requirement that each successive adjustment leads to a smaller sum of squared deviations between calculated and observed eigenvalues. Several variants of the procedure are given, and their application to a number of actual cases is discussed in detail.

Oxidation of asphalt flux with oxides of nitrogen, P. G. Campbell and J. R. Wright, Ind. Engr. Chem. Prod. Res. Develop. 4, No. 2, 121-128 (June 1965).

An asphalt flux of southeastern United States origin was treated with various oxides of nitrogen as the oxidizing gases. Changes in physical and chemical properties were measured by infrared spectroscopy, softening points, and microviscometry. Reaction temperatures did not exceed $166^{\circ} \mathrm{C}$. and gas flow rates were well below those used in the commercial air-blowing of asphalts. Nitrous oxide and nitric oxide, alone, gave very little reaction. Nitrogen dioxide, photosensitized nitrogen dioxide, and a nitric oxide-oxygen mixture reacted with the asphalt flux to produce coating-grade asphalts. The reaction time needed to produce a given asphalt softening point with photosensitized nitrogen dioxide, for example, was $1 / 20$ that needed for air alone. Coating-grade asphalts made with oxides of nitrogen were more stable to photooxidation, and to film rupture at any given rate of shear, than was the commercial asphalt from the same flux. A correlation was observed between the extent of photooxidation of exposed asphalts and the changes in viscoelastic properties.

Vacuum-ultraviolet photolysis of ethane in liquid-nitrogen solution, J. A. Pirog and J. R. MeNesby, J. Chem. Phys. 42, No. 7, 2490-2494 (Apr. 1, 1965).

The photolysis of $\mathrm{C}_{2} \mathrm{H}_{6}$ in liquid nitrogen was studied at $1470 \AA$ It was found that the excited ethylene so produced, whose alternative paths are collisional deactivation and decomposition to acetylene plus hydrogen, was entirely deactivated by nitrogen with the acetylene quantum yield falling to zero at very low conversion.

$$
\begin{gathered}
\mathrm{C}_{2} \mathrm{H}_{6}{ }^{*} \rightarrow \mathrm{C}_{2} \mathrm{H}_{4} \dagger+\mathrm{H}_{2} \\
\mathrm{C}_{2} \mathrm{H}_{4} \dagger+\mathrm{M} \rightarrow \mathrm{C}_{2} \mathrm{H}_{4}+\mathrm{M}
\end{gathered}
$$

The excited ethane formed in the primary process is not deactivated by $10^{12}$ collisions per second with nitrogen. Excited ethylene formed by photolysis of ethylene at $1470 \AA$ is not quenched by the nitrogen but is partially quenched by .001 mole \% NO. Thus, electronically excited ethylene is partially deactivated by collisions at a rate of $10^{9} \mathrm{sec}^{-1}$. No positive evidence for reaction of $\mathrm{CH}_{3} \mathrm{CH}$ with $\mathrm{N}_{2}$ was obtained.

Ther'modynamic properties of neon from 25 to $300{ }^{\circ} \mathrm{K}$ between 0.1 and 200 atmospheres, R. D. McCarty and R. B. Stweart, Advances in Thermophysical Properties at Extreme Temperatures and Pressures, p. 84-97 (Am. Soc. Mech. Engr., New York, N.Y.. 1965).

Selected P- $\rho$-T data for liquid and gaseous neon have been fitted to an analytical function. The selected data are the available experi mental data, supplemented in regions of pressure and temperature where experimental data are not available by values calculated from the theory of corresponding states and a generalized equation of state. Deviation plots are given which indicate the accuracy with which the analytical function represents the experimental data. The uncertainty of the tabulated properties is also estimated. The equation of state and the zero pressure specific heat were used to calculate tables of density, entropy, and enthalpy for selected temperatures and pressures. These properties are also illustrated in temperature-entropy diagrams.

Work function measurements on field emitters with prescribed orientation, J. W. Little, T. E. Madey, and R. Klein, J. Appl. Phys. 36, No. 4, 149-1492 (Apr. 1965).

Field emitters oriented with a prescribed plane perpendicular to the emitter axis can be prepared simply and economically. This involves the use of the spark erosion technique to machine the emitter blanks from a single crystal rod that may be as small as $1 / 8^{\prime \prime}$ diameter. The method is described in detail, and examples of 100 and 111 oriented tungsten emitters are shown.

Adsorption of polymer molecules at low surface coverage, C. A. J. Hoeve, E. A. DiMarzio, and P. Peyser, J. Chem. Phys. 42, No. 7, 2558-2563 (Apr. 1, 1965).

A statistical-mechanical treatment of a polymer molecule adsorbed on a solid surface is given. The surface coverage of adsorbed molecules is assumed to be sufficiently low that the interactions of the adsorbed polymer molecules with each other may be neglected. The partition function is derived for a polymer molecule with sequences of repeating units adsorbed at an interface and with other sequences (loops) held at the surface only at their ends. The assumption of Gaussian statistics for the loops leads to a formulation equivalent to that used for the helix-coil region in DNA molecules. A broad distribution of loop sizes is found, in contrast to Silberberg's theory in which a sharply péaked distribution is assumed. The latter theory predicts also small loops for all values of the adsorption free energy. In contrast, our theory predicts large loops and few units adsorbed for small adsorption free energies and small loops and more units adsorbed for larger adsorption free energies when the chains are sufficiently flexible. This result is also in partial disagreement with earlier theories that predict large loops, even for relatively large adsorption free energies. On the other hand, our theory predicts only a small number of loops and most units at the surface for stiff chains. A relationship between the initial slope of an adsorption isotherm and the molecular weight of the polymer is presented. 
Effects of finite heat capacity on spin-lattice relaxation, R. L. Peterson, Phys. Rev. 137, No. 5A, A1444-A1448 (Mar. I, 1965).

The spin-lattice approach to equilibrium is studied for situations in which the "lattice" heat capacity, is not infinite. It is assumed that the spins and the "lattice" each have a well-defined temperature and that the bath either has been removed or is only very weakly coupled to the lattice. It is shown that asymptotically the magnetization relaxes exponentially with a relaxation time which can be very much different from $T_{1}$ (the spin-lattice relaxation time for an infinite lattice heat capacity), not only in numerical value but in its functional dependence upon temperature, magnetic field, and spin concentration. Some examples are presented in which the effect of the finite lattice is to "lock" the magnetization in at its initial value for times one to two orders of magnitude longer than the ultimate relaxation time.

Elastic resonances in electron scattering from $\mathrm{He}, \mathrm{Ne}, \mathrm{Ar}$, $\mathrm{Kr}, \mathrm{Xe}$, and Hg, C. E. Kuyatt, J. A. Simpson, and S. R. Mielczarek, Phys. Rev. 138, No. 2A, A385-A385-A399 (Apr. 19, 1965).

The transmission of electrons through the rare gases and mercury vapor has been examined as a function of electron energy, with energy resolution of about $0.04 \mathrm{eV}$. Many anomalies (resonances) localized in energy have been observed, totaling eleven in helium, six in neon, two each in argon and krypton, five in xenon, and thirteen in mercury. The interpretation of these resonances in terms of compound negative ion formation is discussed, and in several cases electron configurations are assigned to the negative ions. In helium, neon, xenon, and mercury, sharp decreases in transmission are observed which are attributed to the onset of inelastic processes. Definite identification of the inelastic processes in the case of helium enables calibration of the absolute electron energy scale to within $\pm 0.03 \mathrm{eV}$.

Electronic energy bands in $\mathrm{SrTiO}_{3}$ and related oxide semiconductors, A. H. Kahn and A. J. Leỹendecker, Proc. 1964 Intern. Conf. Phys. of Semiconductors, Paris, pp. 33-39 (Physique des Semiconducteurs, Paris, France, 1964).

A theoretical examination of the electronic energy bands of cubic strontium titanate has been performed by application of the LCAO (linear combination of atomic orbitals) method. Diagonal energies were determined from ionization potentials and crystalline fields based on a point charge model for the ions. The ionic charges were adjusted to give agreement with the observed energy gap. Overlap integrals were estimated from free ion wave functions. For the crystals studied, the calculations led to filled valence bands derived primarily from oxygen $2 p$ orbitals and empty conduction bands derived predominantly from titanium $3 d$ orbitals. In cubic strontium and barium titanates, there are six lowest conduction band ellipsoids lying along $<100>$ directions of $k$-space with minima probably at the edges of the Brillouin zone. The longitudinal mass is about $20-50 m_{0}$ and the transverse mass about $1 m_{0}$. Spin-orbit splitting removes degeneracy at $k=0$ and leads to additional conduction bands several hundredths of an electron volt above the lowest conduction band. Comparison is made with experimental data on conductivity, Hall effect, thermoelectric power, reflectivity, and soft $x$-ray emission. Results are in substantial agreement with experiment.

Identification of energy levels of negative ions, U. Fano and J. W. Cooper, Phys. Rev. 138, No. 2A, A400-A402 (Apr. 19, 1965). Levels of $\mathrm{He}^{-}$at 57.1 and 58.2 and of $\mathrm{Hg}^{-}$at $4.0_{7}, 4.2_{9}$ and $4.8_{7}$, whose observation is described in an accompanying paper, are identified spectroscopically as $2 s^{2} 2 p{ }^{2} \mathrm{P}, 2 s 2 p^{2}{ }_{2}{ }_{D}, 6 s 6 p^{2}{ }^{4} \mathrm{P}_{1 / 2.3 / 2.5 / 2}$, respectively. The identification procedure, which combines elements of spectroscopy and collision theory is described.

Influence of spin paramagnetism on superconductivity, R. A. Kamper, R. S. Collier, and Y. Ohori. Phys. Rev. 137, 1A, A75A77 (Jan. 4, 1965).

The Ginsburg-Landau equations are modified to include a magnetic permeability which varies with the order parameter $\psi$ according to the relation: $\mu=\mu_{s} \psi^{2}+\mu_{n}\left(1-\psi^{2}\right)$. The influence of this on the predicted behavior of a superconducting film in a tangential magnetic field is investigated theoretically. A new value is derived for the upper limit of the critical field for a bulky superconductor and a thin film.

Interpretation of Ar ${ }^{+}$-Ar collisions at $50 \mathrm{keV}, \mathrm{U}$. Fano and W. Lichten, Phys. Rev. Letters 14, No. 16, 627-629 (Apr. 19, 1965). An interpretation of the mechanism of ion-atom collisions is presented and discussed.

Mass-spectrometric study of photoionization, II. H, HD, and $\mathbf{D}_{2}$, V. H. Dibeler, R. M. Reese, and M. Krauss, J. Chem. Phys. 42, No. 6, 2045-2048 (Mar. 15, 1965).

Mass spectrometric techniques have been used to obtain the photoionization efficiency curves for $\mathrm{H}_{2}, \mathrm{HD}$, and $\mathrm{D}_{2}$ in the energy range 815 to $700 \AA$ ( 15.2 to $17.7 \mathrm{eV})$. A qualitative description of the observed autoionization process, based on a theory proposed by Fano, is applied to an analysis of the results.

Multiple-band conduction in n-type rutile $\left(\mathbf{T i O}_{2}\right)$, J. H. Becker and W. R. Hosler, Phys. Rev. 137, No. 6A, Al872-A1877 (Mar. 15, 1965).

The existence of multiple band conduction in $n$-type rutile for temperatures above $\sim 40^{\circ} \mathrm{K}$ is deduced from studies of the Hall coefficients and electrical conductivities from $\sim 2$ to $600{ }^{\circ} \mathrm{K}$. This investigation emphasizes the anisotropy of the Hall coefficients, i.e., the Hall effect measured with magnetic fields along the $a$-and the $c$-axis, respectively $\left(R_{a}\right.$ and $\left.R_{c}\right)$. The pronounced temperature dependence of the ratio of these two coefficients can most easily be interpreted on the basis of two competing conduction processes. Measurements on samples with widely differing charge carrier concentrations prove that the conduction processes involved are due to intrinsic energy states of the crystal. The energy separation between the lowest conduction band and the bottom of the next higher one is calculated to be $0.05 \pm 0.01 \mathrm{eV}$, where the indicated uncertainty denotes estimated limits of error. These concepts are consistent with recent band structure calculations. Impurity and surface conduction are shown to be negligible.

On the behavior of the compressibility along the critical isotherm, S. Y. Larsen and J. M. H. L. Sengers, Advances in Thermophysical Properties at Extreme Temperatures and Pressures, pp. 74-75 (Am. Soc. Mech. Engr., New York, N.Y., 1965).

In this note we comment on the use of analytical functions to describe the behavior of a system in the critical region, as proposed by Ulybin and Malyshenko, among others. We also investigate an apparent sharp disagreement noted by these authors between density gradients obtained optically and those derived from P-V-T data, in the critical region. We think that much of the disagreement arises from the way the P-V-T data were analyzed. We conclude that in the critical region the pressure vs. density isotherms are much flatter than has been inferred from P-V-T work. The consequent large gravitational effect together with the difficulty of determining the slope of the isotherm severely limit the use of P-V-T measurement for the investigation of detailed behavior of thermodynamic quantities in the vicinity of the critical point.

On the validity of the Lorentz-Lorenz equation near the critical point, S. Y. Larsen, R. D. Mountain, and R. Zwanzig, J. Chem. Phys. 42, No. 6, 2187-2190 (Mar. 15, 1965).

Corrections to the Lorentz-Lorenz equation for the refractive index of a fluid have been evaluated, near the critical point, using Yvon's statistical mechanical theory of the refractive index, together with the Ornstein-Zernike asymptotic form of the two-particle correlation function. For argon, with reasonable values for the numerical parameters, the correction is smaller than one part in $10^{4}$.

Polar modes of lattice vibration and polaron coupling constants in rutile $\left(\mathbf{T i O}_{2}\right)$, D. M. Eagles, J. Phys. Chem. Solids 25, No. 11, 1243-1251 (Nov. 1964).

Published experimental infrared reflection data are analyzed to obtain information about the long wavelength polar modes of lattice vibration in rutile $\left(\mathrm{TiO}_{2}\right)$. Weighted sums of squares of effective charges are found, and are compared with the same quantities calculated on a simple ionic model. The continuum polarization model of electron-phonon interactions is extended to apply to crystals with several types of longitudinal polar phonons, and the results are used to discuss polaron theory in rutile. 
Polaron coupling constants in $\mathrm{SrTiO}_{3}$, D. M. Eagles, J. Phys. Chem. Solids 26, No. 3, 672 (Mar. 1965).

Using the method described in an article on rutile (D. M. Eagles, to appear), the author has calculated the long wavelength longitudinal polar mode frequencies and coupling constants in $\mathrm{SrTiO}_{3}$.

Pressure dependence of the internal field at the $\mathrm{Co}^{59}$ nucleus in a $99.5 \% \mathrm{Ni-0.5 \%}$ Co alloy, L. H. Bennett, J. Appl. Phys. 36, No. 3, Pt. 2, 942-943 (Mar. 1965).

The room temperature nuclear magnetic resonance absorption of $\mathrm{Co}^{59}$ in an alloy of 0.5 percent $\mathrm{Co}$ in $\mathrm{Ni}$ has been measured under hydrostatic pressures of up to $7 \mathrm{kbars}$. The change in the resonance frequency with pressure is $\Delta \nu / \rho=159 \pm 5 \mathrm{~Hz} / \mathrm{bar}$. This is in the same direction (increasing frequency for increasing pressure) as for $\mathrm{Ni}^{61}$ in $\mathrm{Ni}$. The ratio of the resonance frequency to the change in frequency with pressure $\nu: \Delta \nu / \rho$ is $700 \mathrm{kbar}$ for $\mathrm{Co}^{59}$ and 1100 kbar for $\mathrm{Ni}^{61}$ in $\mathrm{Ni}$. The internal field at the $\mathrm{Co}^{59}$ nucleus decreases with increasing temperature more slowly than that at the $\mathrm{Ni}^{61} \mathrm{nu}$ cleus in Ni-rich Ni-Co alloys. This discrepancy in the temperature dependences remains as large, when plotted at constant volume, as it was at constant pressure.

Structure of electrodeposited lead dendrites, F. Ogburn, C. Bechtoldt, J. B. Morris, and A. deKoranyi, J. Electrochem. Soc. 112 , No. 6, 574-577 (June 1965).

Electrodeposited lead dendrites were grown and examined by x-ray diffraction and metallographically. Their structure was essentially that of two crystals having a twist relation about a common [111 pole which was normal to the flat surface of the two dimensional dendrites. Each dendrite contained many small voids or channels. The direction of growth was either about halfway between a $<211>$ direction of one crystal and a neighboring $\langle 211\rangle$ direction of the second crystal or halfway between $\langle 110\rangle$ direction.

SU(6) Clebsch-Gordan coefficients for the product $\mathbf{3 5} \times \mathbf{5 6}$, J. C. Carter, J. J. Coyne, and S. Meshkov, Phys. Rev. Letters 14, No. 13, 523-526 (Mar. 29, 1965).

SU(6) Clebsch-Gordan coefficients for the product $35 \times 56$ have been calculated. They have been used to predict a new set of scattering amplitudes which relate widely different final states for reactions in which mesons are incident on proton targets.

The correlation of experimental pressure-density-temperature and specific heat data for parahydrogen, H. M. Roder, L. A. Weber, and R. D. Goodwin (Proc. XI Intern. Congress Refrigeration, Munich, Germany, Aug. 1963), Prog. Refrig. Sci. Technol. 1, 187-191 (1963).

The use of hydrogen in space vehicles and in nuclear devices demands the accurate knowledge of its mechanical and thermal properties.

As mechanical properties of parahydrogen nearly 1200 closely spaced $\mathrm{P}-\rho$ - $\mathrm{T}$ points have been measured between 14 and $100{ }^{\circ} \mathrm{K}$ and between 2 and $350 \mathrm{~atm}$. The P- $\rho$-T surface was approximated by a large number of polynomials coupled with appropriate interpolation schemes. Use of the virial expansion allows extrapolation to pres. sures below 2 atm.

Thermal properties may be obtained after relating the experiment above to a second one in which the heat capacity at constant volume was determined for a variety of experimental conditions. At temperatures below critical these heat capacities are used as primary data, while at temperatures above critical they serve as check on the correlation between the statistically calculated specific heats and the P- $\rho$ - $T$ data. Further tests of the correlation arise when calculating thermodynamic functions.

From this correlation it is now possible to compute as function of pressure and temperature such quantities as specific volume, enthalpy, entropy, specific heat at constant volume, specific heat at constant pressure, sonic velocity, the Joule-Thomson coefficient and the heats of vaporization.

Transition from resonant to non-resonant line shape in microwave absorption, A. Ben-Reuven, Phys. Rev. Letters 14, No. 10, 349-351 (Mar. 8, 1965).

A new expression is suggested to account for the variation with pressure of the spectral intensity distribution in microwave absorp- tion lines of gases, with specific application to the ammonia inversion spectrum. This expression departs from the conventional Van Vleck Weisskopf expression by adding a new coupling parameter which is proportional to the gas density. The theory is tested by applying it to the observations of Bleaney and Loubser and of Birnbaum and Maryott on ammonia.

Infrared emission spectrum of $\mathrm{HBr}$ excited in an electric discharge. Datermination of molecular constants, T. C. James and R. J. Thibault, J. Chem. Phys. 42, No. 4, 1450-1457 (Feb. 1965).

The infrared emission spectra of $\mathrm{HBr}^{79}$ and $\mathrm{HBr}^{81}$ have been observed by exciting $\mathrm{HBr}$ in an electric discharge. Lines in the $1-0,2-1$, and $3-2$ bands have been measured to an accuracy of the order of $0.01 \mathrm{~cm}^{-1}$. Pure rotational transitions of $\mathrm{HBr}^{79}$ and $\mathrm{HBr}^{81}$ which were not resolved have also been observed and meas. ured with an accuracy of the order of $0.2 \mathrm{~cm}^{-1}$. Values are reported for $\omega_{e}, \omega_{e} x_{e}, \omega_{e} y_{e}$ (only limits for this constant), $\mathrm{B}_{e}, \mathrm{D}_{e}, \alpha_{e}, \beta_{e}, \gamma_{e}, \delta_{e}$, and approximate values of $\mathrm{H}_{0}$ and $\mathrm{H}_{1}$ are also obtained. The results are found to be in agreement with Dunham's theory. Values of the potential constants $a_{1}, a_{2}$, and $a_{3}$ are calculated. The $\mathrm{B}_{e}$ values for $\mathrm{HBr}^{79}$ and $\mathrm{HBr}^{81}$ agree with calculations based on microwave measurements of $\mathrm{DBr}^{79}$ and $\mathrm{DBr}^{81}$.

Mass spectrometric study of photoionization. III. Methane and methane-d ${ }_{4}$, V. H. Dibeler, M. Krauss, R. M. Reese, and F. N. Harllee, J. Chem. Phys. 42, No. 11, 3791-3796 (June 1965). Photoionization efficiency curves for the molecule and fragment ions of $\mathrm{CH}_{4}$ and $\mathrm{CD}_{4}$ are obtained in the wavelength region 1000 to $600 \mathrm{~A}$. The electronic structure of the molecule ion is related qualitatively to the shape of the parent ionization efficiency curve and the implications of the complicated vibronic behavior of the $\mathrm{CH}_{4}^{+}$ion are discussed. A qualitative explanation is given for the observed isotope effect on the parent ionization efficiency curve and on the fragment ion threshold energies. More nearly correct values of $\mathrm{I}\left(\mathrm{CH}_{4}\right)=12.71 \mathrm{eV}$ and $\mathrm{I}\left(\mathrm{CD}_{4}\right)=12.87 \mathrm{eV}$ are obtained. Other thermochemical values deduced from the study are: $\mathrm{D}\left(\mathrm{CH}_{3}-\mathrm{H}\right)$ $=4.41 \mathrm{eV}, \mathrm{D}\left(\mathrm{CD}_{3}-\mathrm{D}\right)=4.55 \mathrm{eV}, \mathrm{D}\left(\mathrm{CH}_{2}-\mathrm{H}\right)=4.87 \mathrm{eV}$, and $\mathrm{H}_{\mathrm{f}}\left(\mathrm{CH}_{2}\right)$ $=4.07 \mathrm{eV}$. Zero-point energy differences for methyl and methylene ions and neutrals are also estimated

Phase equilibria studies in mixed systems of rare earth and other oxides, R. S. Roth, Book, Progress in Science and Technology of the Rare Earths, ed. L. Ewring 1, 167-202 (Pergamon Press, Inc., New York, N.Y., 1964).

This paper is a review of the phase equilibra data available on binary systems containing a rare earth oxide, $\mathrm{Y}_{2} \mathrm{O}_{3}$ or $\mathrm{Sc}_{2} \mathrm{O}_{3}$ as one component. The review is limited to the oxides of the trivalent rare earth ions only. The phase diagrams are shown when previously published and unit cell dimensions of all compounds are also given where known. From a discussion of the problems involved in the accurate measurement of high temperatures it is concluded that accurate melting point standards are needed for the temperature range $2000-2400{ }^{\circ} \mathrm{C}$ in air.

The value of the Faraday, W. J. Hamer and D. N. Craig, J. Electrochem. Soc. 111, No.12, 1434 (Dec. 1964).

This is a brief communication addressed to the Editor of the Journal of the Electrochemical Society briefly discussing the value of the Faraday.

\section{Other NBS Publications}

J. Res. NBS 69B (Math. and Math. Phys.), No. 3 (July-Sept. 1965), 75 cents.

A development of the theory of errors with reference to economy of time. M. D. Hersey. Prefatory note by C. Eisenhart.

Transversals and matroid partition. J. Edmonds and D. R. Fulkerson.

Some $L_{2}$ Markoff inequalities. .L. F. Shampine.

Some theorems on the permanent. R. A. Brualdi and M. Newman.

On Kirchoff's law and its generalized application to absorption and emission by cavities. F. J. Kelly.

On a relation between two-dimensional Fourier integrals and series of Hankel transforms. J. V. Cornacchio and R. P. Soni. 
On convex metrics. C. Witzgall.

Some extensions of Banach's contraction theorem. P. R. Meyers.

A variant of the two-dimensional Riemann integral. A. J. Goldman.

The use of finite polynomial rings in the factorization of the general polynomial. D. B. Lloyd.

A primal (all-integer) integer programming algorithm. R. D. Young.

J. Res. NBS 69C (Eng. and Instr.), No. 4 (Oct.-Dec. 1965), 75 cents.

Some applications of the wave front shearing interferometer. J. B. Saunders.

Precision method for evaluating primary aberrations of lenses with a Twyman interferometer. J. B. Saunders.

Comparators for voltage transformer calibrations at NBS. W. C. Sze.

Voltage dependence of precision air capacitors. J. Q. Shields.

Single crystal x-ray diffraction at high pressures. C. Weir, S. Block, and G. Piermarini.

The Sondheimer-Wilson-Kohler formula in platinum resistance thermometry. R. J. Corruccini.

Stress analysis of tape-wound magnet coils. J. Hord.

Centerline correction for precision roughness specimens. J. L. Chamberlin.

Electric currents and potentials resulting from the flow of charged liquid hydrocarbons through short pipes. M. R. Shafer, D. W. Baker, and K. R. Benson.

A transistor screening procedure using leakage current measurements. G. T. Conrad and D. C. Shook.

Radio Sci J. Res. NBS/USNC-URSI, 69D, No. 8, (Aug. 1965), $\$ 1.00$.

“Ultra Low Frequency Electromagnetic Fields" Papers

Preface to "Ultra Low Frequency Electromagnetic Fields" Papers. W. H. Campbell and S. Matsushita.

Solar wind and its interaction with the magnetosphere. C. P. Sonnett.

Schumann resonances. J. Galejs.

Earth-ionosphere cavity resonances and the propagation of ELF radio waves. J. R. Wait.

Resonances of the earth-ionosphere cavity observed at Cambridge, England. M. J. Rycroft.

Experimental results on the dynamics of the $F$ region. W. Becker, R. Rüster, and J. Klostermeyer.

Regular oscillations near $1 \mathrm{c} / \mathrm{s}$ observed at middle and low latitudes. L. Tepley.

Preliminary results of a micropulsation experiment at a conjugate points. R. E. Gendrin and V. A. Troitskaya.

Some characteristics of geomagnetic pulsations at frequencies near $1 \mathrm{c} / \mathrm{s}$. W. H. Campbell and E. C. Stiltner.

Propagation of hydromagnetic waves in the magnetosphere. M. Sugiura.

Ionospheric pertubation (the roles played by the ionosphere in geomagnetic pulsations). S. Matsushita.

Effects of induced earth currents on low-frequency electromagnetic oscillations. A. T. Price. Equatorial effects. R. Hutton.

Interpretation of early magnetic transients caused by high-altitude nuclear detonations. S. L. Kahalas and P. Newman. man.

\section{Regular Contributions}

A note on the application of pulse compression techniques to ionospheric sounding. D. C. Coll and J. R. Storey.

Comments on a paper "Measurement of the phase velocity of VLF propagation in the earth ionosphere waveguide" by F. K. Steele and C. J. Chilton. H. F. Bates.

Reply to H. F. Bates' Comments on "Measurement of the phase velocity of VLF propagation in the earth ionosphere waveguide" by F. K. Steele and C. J. Chilton. F. K. Steele and C. J. Chilton.

Radio Sci. NBS/USNC-URSI, 69D, No. 9, (Sept. 1965), $\$ 1.00$.

Ground-based passive probing using microwave spectrum of oxygen. E. R. Westwater.

Response of NBS microwave refractometer cavities to atmospheric variations. R. O. Gilmer, R. E. McGavin, and B. R. Bean.
Effects of rocket outgassing on rf experiments. W. Pfister and J. C. Ulwick.

Further analysis of propagation of plasma waves in a "spoke-wheel" magnetic field. Richard R. Gold.

Measurement of group velocity of $17.8 \mathrm{kHz}$ VLF radio waves. W. D. Westfall.

On the radio noise level at low and very low frequencies in polar regions. T. Stockflet Jørgensen.

Experimental study on the circular loop antenna immersed shallowly in a conducting medium. Keigo Iizuka.

Directivity of uniformly spaced optimum endfire arrays with equal sidelobes. M. T. Ma.

Extension of Fock theory for currents in the penumbra region. V. H. Weston.

Isometric-circle interpretation of bilinear transformation and its application to VSWR minimization. J. G. Rudolph and D. K. Cheng.

Magneto-ionic propagation in inhomogeneous media. Part I. Transverse propagation. B. K. Banerjea.

Magneto-ionic propagation in inhomogeneous media. Part II. Oblique propagation. B. K. Banerjea.

Editorial comment on the scientific papers of Lord Rayleigh (John William Strutt). J. R. W ait.

Radio Sci. J. Res. NBS/USNC-URSI, 69D, No. 10, (Oct. 1965), \$1.00.

Irreversible power and radiation resistance of antennas in anisotropic ionized gases. K. S. H. Lee and C. H. Papas.

Scattering resonances of a cylindrical plasma. W. M. Leavens.

Radiation patterns from plasma enclosed cyclindrical hypersonic vehicles. J. H. Harris, A. T. Villeneuve, and L. A. Broca.

The Schumann resonances. R. K. Cole, Jr.

Atmospheric radio noise bursts in the LF band at Bangalore. S. V. C. Aiya and K. N. Lakshminarayan.

Influence of finite ground conductivity on the propagation of VLF radio waves. J. R. Wait and K. P. Spies.

Model experiments on propagation of groundwaves across an abrupt boundary at perpendicular incidence. R. J. King and S. W. Maley.

Radio Sci. J. Res. NBS/USNC-URSI, Vol. 69D, No. 11 (Nov.

$1965), \$ 1.00$.

Propagation of pulses in dispersive media. J. R. Wait.

An anisotropic electron velocity distribution for the cyclotron absorption of whistlers and VLF emissions. H. Guthart.

Nose whistler dispersion as a measure of magnetosphere electron temperature. H. Guthart.

Interference rejection capability of a switched radiometer. R. E. Clapp.

Atmospheric breakdown limitations to optical maser propagation. R. G. Tomlinson.

Phase steps and amplitude fading of VLF signals at dawn and dusk. D. Walker.

Propagation in a model terrestrial waveguide of nonuniform height theory and experiment. E. Bahar and J. R. Wait.

Comments on H. Volland's "Remarks on Austin's Formula." J. R. Wait.

The path integrals of LF/VLF wave hop theory. L. A. Berry and M. E. Chrisman.

Reactive loading of arbitrarily illuminated cylinders to minimize microwave backscatter. Kun-Mu Chen.

On the statistical theory of electromagnetic waves in a fluctuating medium (II) Mathematical basis of the analogies to quantum field theory (a digest). K. Furutsu.

Radio Sci. J. Res. NBS/USNC-URSI, Vol. 69D, No. 12 (Dec. 1965), \$1.00.

Symposium on Planetary Atmospheres and Surfaces, May 1965:

I Session: Jupiter, as observed at long radio waves.

II Session: Jupiter, as observed at short radio waves.

III Session: Passive radio observations of Venus, Saturn. Mercury, Mars, and Uranus.

IV Session: Passive radio observations of the Moon.

V Session: Radar observations of the planets.

VI Session: Radar observations of the Moon. 
Selected tables of atomic spectra. Atomic energy levels and multiplet tables Si II, Si III, Si IV, C. E. Moore, NSRDS-NBS3, Sec. 1 (June 25, 1965), 35 cents.

Electrical engineering units and constants, NBS Misc. Publ. 268 (June 1965), 10 cents, $\$ 6.26$ a 100.

Transmission loss predictions for tropospheric communication circuits, P. L. Rice, A. G. Longley, K. A. Norton, and A. P. Barsis. NBS Tech. Note 101, Vol. I (May 7, 1965), \$1.00.

Transmission loss predictions for tropospheric communication circuits, P. L. Rice, A. G. Longley, K. A. Norton, and A. P. Barsis, NBS Tech. Note 101, Vol. II (May 7, 1965), \$1.00.

On the effect of heavy ions on LF propagation, with special reference to a nuclear environment, J. R. Johler and L. A. Berry, NBS Tech. Note 313 (June 7, 1965), 45 cents.

Stability of two-phase annular flow in a vertical pipe, S. Jarvis, Jr. NBS Tech. Note 314 (June 7, 1965), 55 cents.

Grading of abrasive grain for grinding, CS271-65 (April 12, 1965). Supersedes SPR R118-50.

Gas chromotographic determination of the moisture content of grain. E. L. Weise, R. W. Burke, and J. K. Taylor, (Proc. 1963 Intern. Symp. Humidity and Moisture, Wash. D.C.), Book, Humidity and Moisture, ed. A. Wexler, Vol. IV, Principles and Methods of Measuring Moisture in Liquids and Solids, ch. 1. pp. 3-6 (Reinhold Publ. Corp.. New York, N.Y., 1965).

Isotopic fractionation of uranium in sandstone, Powder River Basin. Wyoming, and Slick Rock District, Colorado, J. N. Rosholt. A. P. Butler, E. L. Garner, and W. R. Shields, Econ. Geol. 60, No. 2. 199-213 (Mar.-Apr. 1965).

On the twilight sodium emission-2. A theoretical model of sodium abundance, M. Gadsden, Ann. Geophys. 20, No. 4, 383-396 (Oct. Dec. 1964).

Strength of fingernails, R. W. Young, S. B. Newman, and R. J. Capott. J. Invest. Dermatol. 44, No. 5, 358-360 (Dec. 23. 1964).

A miniature helium turbo-expander for cryogenic refrigeration systems, M. T. Norton, (Proc. XI Intern. Congress Refrigeration. Munich, Germany, Aug. 1963), Prog. Refrig. Sci. Technol. 1, $131-135$ (1963).

A simple method for measuring the amount of granular materials in sulfur mortars, C. L. Thompson, Mater. Res. Std. 5, No. 5, 242243 (May 1965).

A waveguide noise standard, C. K. S. Miller, W. C. Daywitt, and E. Campbell, (Proc. Intern. Measurements Conf.), Acta IMEKO 3, 371-382 (1964).

A standard for extremely low values of spectral irradiance. R. Stair, W. B. Fussell, and W. E. Schneider, Appl. Opt. 4, No. 1, 85-89 (Jan. 1965).

Commercial carbon composition resistors as pressure transducers, C. E. Miller, J. W. Dean, and T. M. Flynn, Rev. Sci. Instr. 36, 231-232 (Feb. 1965).

Human engineering in the design of a console for the comparison of volt boxes, P. H. Lowrie, Jr., 19th Annual Instr. Soc. Am. Conf. Exhibit, Preprint No. 12.1-3-64, pp. 1-8 (Oct. 12-15, 1964).

Maintenance of maring electronic equipment by personnel not trained in electronic maintenance, G. Shapiro and G. J. Rogers, Proc. Annual Tanker Conf. American Petroleum Institute, pp. A-1-A-18 (June 1965).

Optical instrumentation for the biologist: Microscopy, J. R. MeyerArendt, Appl. Opt. 4, No. 1, 1-9 (Jan. 1965).

Precision detector for complex insertion ratio measuring systems, C. M. Allred and R. A. Lawton, IEEE Trans. Instr. Meas. IM-13, No. 2 \& 3, 76-81 (June-Sept. 1964).

Stress corrosion cracking of metals, H. L. Logan, Metals Engr. Quart. 5, No. 2, 32-38 (May 1965).

The effect of a fatigue crack on the fatigue strength of an aluminum alloy, J. A. Bennett, Mater. Res. Std. 5, No. 5, 235-239 (May 1965).

The role of cryogenics in the production of high and ultra-high vacuum, L. O. Mullen and M. J. Hiza, Cryogenics 4, No. 6. 387394 (Dec. 1964).

A method for the computauun of the error function of a complex variable, O. N. Strand, Math. Comp. XIX, No. 89, 127-129 (Jan. 1965).

Bounds tor class numbers, M. Newman, Proc. Pure Mathematics, Vol. VIII. Theory of Numbers, p. 70-77 (Am. Math. Soc., 1965).

Comment on "The use of transtorms to sum array factors, M. T. Ma, IEEE Trans. Ant. Prop. AP-13, No. 1, 174 (Jan. 1965).
Distribution of student's $t$ in samples from a rectangular universe, M. M. Siddiqui, Rev. Intern. Stat. Inst. 32, No. 3, 242-250 (1964).

Mathematical programming models for selection of diets to minimize weighted radionuclide intake, H. J. Bracken, Environmental Health Series: Radiological Health, Public Health Serv. Publ. 999-R-4 (Dept. Health, Education, and Welfare, Wash. D.C., Aug. 1963).

A comparison between the National Bureau of Standards twopressure humidity generator and the National Bureau of Standards hygrometer, S. Hasegawa, R. W. Hyland, and S. W. Rhodes, (Proc. 1963 Intern. Symp. Humidity and Moisture, Wash., D.C.), Book, Humidity and Moisture, Measurement and Control in Science and Industry, ed. A. Wexler. Vol. 3, Fundamentals and Standards, ch. 22, pp. 455-459 (Reinhold Publ. Corp., New York, N.Y., 1965).

A pneumatic bridge hygrometer for use as a working humidity standard, L. Greenspan, (Proc. 1963 Intern. Symp. Humidity and Moisture, Wash., D.C.), Book, Humidity and Moisture. Measurement and Control in Science and Industry, ed. A. Wexler, Vol. 3, Fundamentals and Standards, ch. 20, pp. 433-443 (Reinhold Publ. Corp. New York, N.Y., 1965).

Letter to the Editor, C. H. Page, Metrologia 1, No. 2, 73-74 (Apr. 1965). The evolution of designed experiments, W. J. Youden, Proc. IBM Scientific Computing Symp. Statistics, pp. 59-67 (West Chester County, New York, Sept. 1963).

The NBS standard hygrometer. A. Wexler and R. W. Hyland (Proc. 1963 Intern. Symp. Humidity and Moisture, Wash., D.C.), Book, Humidity and Moisture. Measurement and Control in Science and Industry, ed. A. Wexler, Vol. 3. Fundamentals and Standards, ch. 19. pp. 389-431 (Reinhold Publ. Corp., New York, N.Y., 1965).

Characteristics of a Raman laser excited by an ordinary ruby laser, H. Takuma and D. A. Jennings. Proc. IEEE 53, No. 2, 146-149 (Feb. 1965).

Determination of the probability distribution of the number of secondary electrons, Z. Bay and G. Papp, IEEE Trans. Nuclear Sci. NS-11, No. 3, 160 (June 1964); Elec. Commun. 40, No. 1, 134 (1965).

Drift-free Mossbauer spectrometer, F. C. Ruegg, J. J. Spijkerman. and J. R. DeVoe, Rev. Sci. Instr. 36, No. 3, 356-359 (Mar. 1965).

Ice nucleation by photolyzed silver iodide, G. Burley, Phil. Mag. 10, 527 (Sept. 1964).

Longitude distribution of proton flares, C. S. Warwick, Astrophys. J. 141, No. 2, 500-504 (Feb. 15, 1965).

Plans for proposed new tables of the thermodynamic properties of moist air, J. C. Davis, T. K. Faison, Jr., and P. R. Achenbach (Proc. 1963 Intern. Symp. Humidity and Moisture, Wash., D.C.), Book, Humidity and Moisture, Measurement and Control in Science and Industry, ed. A. Wexler. Vol. 3. Fundamentals and Standards, ch. 11, pp. 315-320 (Reinhold Publ. Corp., New York, N.Y. 1965).

Optical quenching of photoconductivity near the band edge in CdS. L. Grabner. Phys. Rev. Letters 14, No. 14, 551-554 (Apr. 5. 1965). Stimulated Brillouin scattering in the off-axis resonator, $\mathrm{H}$. Takuma and D. A. Jennings, Appl. Phys. Letters 5, 239-241 (Dec. 1964).

The absolute photometry of the zodical light. L. L. Smith, F. E. Roach, and R. W. Owen, Planet. Space Sci. 13, 207-217 (Pergamon Press Ltd., Northern Ireland, 1965).

X-ray spectrochemical analysis of material: cement and dental alloys, B. L. Bean and B. W. Mulligan. Am. Soc, Testing Mater. Spec. Tech. Publ. 373, Application of Advanced and Nuclear Physics to Testing Materials, pp. 25-45 (June 17, 1965).

Measurement and standardization of LF to UHF electrical quantities. Sketch of recent world-wide developments, M. C. Selby, Prog. Radio Sci. 1960-1963, Vol. I. Radio Standards and Measurements, pp. 45-55 (Elsevier Publ. Co., Amsterdam, The Netherlands, 1965).

Radio meteorology, J. W. Herbstreit, Science 147, No. 3653, 76-78 (Jan. 1, 1965).

Stratospheric moisture measurements using infrared spectroscopy, D. M. Gates, (Proc. 1963 Intern. Symp. Humidity and Moisture, Wash., D.C.), Book, Humidity and Moisture Measurement and Control in Science and Industry, Vol. 2, Applications, Sec. VI, pp. 446-449 (Reinhold Publ., Corp., New York, N.Y., 1965).

The use of electromagnetic signals emitted from nuclear explosions to study long-range VLF propagation, A. G. Jean and J. R. Wait, J. Geophys. Res. 70, No. 5, 1258-1261 (Mar. 1, 1965). 
The uses of oblique ionograms in frequency utilization, K. Davies, ITU Telecommun. J. 31, No. 10, 1-7 (Oct. 1964).

Tropospheric propagation, P. L. Rice and J. W. Herbstreit, Advan. Electron. Electron Phys. 20, 199-259 (1964).

Acid bases in analytical chemistry, I. M. Kolthoff, S. Bruckenstem, and R. G. Bates, Interscience Reprint from Kolthoff-Elving "Treatise on Analytical Chemistry", Pt. I. Sec. B, ch. 10, pp. 361-542 (Interscience Publ. Inc., New York, N.Y., 1965).

Acids and bases in alcohol-water solvents, R. G. Bates, Chem. Chem. Ind. (Japan) 18, 680-685 (May 1965).

Configuration interaction calculation of $\mathrm{H}_{3}$ and $\mathrm{H}_{2}$. C. Edmiston and M. Krauss, J. Chem. Phys. 42, No. 4, 1119 (Feb. 1965).

Constancy of a modified Weston standard cell over long periods, W. C. Bosburgh and R. G. Bates, J. Electrochem. Soc. III, No. 8. 997-988 (Aug. 1964).

Crystal structure of gamma-dicalcium silicate, D. K. Smith, A. Majumdar, and F. Ordway, Acta. Cryst. 18, 787 (Apr. 1965).

Designation of ligand positions in coordination complexes. R. F. Pasternack and P. M. McDonnell, Inorg. Chem. 4, No. 4, 600-602 (Apr. 1965).

Determination of reducing end-groups by reactions with $\mathrm{C}^{14}$-labeled cyanide, H. S. Isbell, Book, Methods in Carbohydrate Chemistry, ed. R. L. Whistler, 5, 249-250 (Academic Press Inc., New York, N.Y., 1965).

Direct observation of the decomposition of multiply charged ions into singly charged fragments, K. E. McCulloh, T. E. Sharp, and H. M. Rosenstock, J. Chem. Phys. 42, No. 10, 3501-3509 (May 1965).

Electron impact studies of aromatic hydrocarbons. III. Anzulene and naphthalene, R. J. Van Brunt and M. E. Wacks, J. Chem. Phys. 41, No. 10, 3195-3199 (Nov. 15, 1965).

Electron paramagentic resonance and the primarily $3 \mathrm{~d}$ wavefunctions of the tetrachlorocuprate ion, M. Sharnoff. J. Chem. Phys. 42, No. 10, 3383-3395 (1965).

Electron paramagnetic resonance spectra of zinc-doped copper acetate monohydrate, G. F. Kokoszka, H. C. Allen, Jr., and G. Gordon, J. Chem. Phys. 42, No. 10, 3693-3697 (May 15, 1965).

Electron paramagnetic resonance spectrum of bis-8-hydroxyquinolate copper (II) dihydrate, G. F. Kokozska, H. C. Allen, Jr., and G. Gordon. J. Chem. Phys. 42, No. 10, 3730-3731 (May 15. 1965).

Extinction coefficients of triplet $\leftrightarrow$ triplet transitions in aromatic compounds, R. A. Keller and S. G. Hadley, J. Chem. Phys. 42, No. 7, 2382 (Apr. 1965)

Franck-Condon factors for polyatomic molecules. T. E. Sharp and H. M. Rosenstock, J. Chem. Phys. 41, No. 11, 3453 (Dec. 1, 1964).

High-precision coulometric titrations with special reference to the determination of uranium, J. K. Taylor and G. Marinenko, Proc. Conf. High-Precision Analysis of Substances of Interest to Nuclear Energy. Jan. 18-22, 1965 pp. 147-161 (Bureau Central des Mesures Nuclaires, Brussels, Belgium, 1965).

High pressure single crystal studies of ice VI, S. Block, C. E. Weir, and G. J. Piermarini, Science 148, 947 (1965).

High temperature microwave spectroscopy: AlF and AlCl, D. R. Lide, J. Chem. Phys. 42, No. 3, 1013-1018 (Feb. 1965).

Improved measurement of the electric dipole moment of the hydroxyl radiacal, F. X. Powell and D. R. Lide, J. Chem. Phys. 42, No. 12, 4201-4202 (June 1965).

Interaction of carbon dioxide with carbon adsorbents below $400{ }^{\circ} \mathrm{C}$. V. R. Deitz, F. G. Carpenter, and R. G. Arnold, Carbon 1, 245 (1964).

Isotopic fractionation of uranium related to roll features in sandstone, Power River Basin, Wyoming and Colorado Plateau, J. N. Rosholt, A. P. Butler, E. L. Garner, and W. R. Shields, Econ. Geol. 60, No. 2, 199-213 (Mar.-Apr. 1965).

Method of obtaining a range of current densities with a resistive cathode, M. Brenner and A. Brenner, Plating 56, No. 6, 527-530 (June 1965).

National Standard Reference Data Program, E. L. Brady and S. A. Rossmassler, D. C. Libraries 35, No. 4, 57-61 (Oct. 1964).

Negative surface ionization of complex molecules, J. T. Herron, H. M. Rosenstock, and W. R. Shields, Nature 206, No. 4984, 611 (May 1965).

Nonequilibrium chemical excitation and chemical pumping of lasers, K. E. Shuler, T. Carrington, and J. C. Light, Appl. Opt. Suppl. 2 , pp. 81-104 (1965).

Photolysis of ethane at the argon resonance lines 1067 and $1048 \AA$. A. H. Laufer and J. R. McNesby, J. Chem. Phys. 42, No. 9. 3329-3330 (May 1. 1965).
Photooxidation of asphalts in the presence of ozone, J. R. Wright and P. G. Campbell, ACS Div. of Petroleum Chem. Preprints 9, No. 3, 161 (Aug. 1964).

Precise assay of copper using small samples, T. J. Murphy and J. K. Taylor, Anal. Chem. 37, No. 7, 929-931 (June 1965).

Pressure-induced trapping phenomenon in silver iodide, H. C. Duecker and E. R. Lippincott, Science 146, 1295-1297 (1964).

Pyrolytic technique, G. M. Brauer, J. Polymer Sci., Pt. C, No. 8, 3-26 (1965).

Radiochemical methods of analysis (Report on Salzburg Conference), W. W. Meinke, Science 147, No. 3654, 182-183 (Jan. 1965).

Recommended materials and practices for use with cryogenic propellants, A. F. Schmidt, AIR 839, 29 pages (SAE Inc., New York, N.Y., Jan. 1965).

Rotational constants of excited vibrational states of ${ }^{14} \mathrm{~N}^{16} \mathrm{O}$, W. J. Lafferty and D. R. Lide, J. Mol. Spectry. 14, No. 4, 407-408 (Dec. 1964).

Second order effects in the phosphorescene of benzophenone crystals at $77^{\circ}$ K, R. A. Keller, J. Chem. Phys. 42, No. 11, 4050-4051 (June 1965).

Spectrophotometric determination of the rate of dissociation of tetrafluorohydrazine behind a shock wave, L. M. Brown and B. Darwent, J. Chem. Phys. 42, No. 6, 2158-2165 (Mar. 15, 1965).

Standardization of plastics in the U.S., G. M. Kline, Courrier de la Normalisation No. 182, pp. 280-282 (Mar.-Apr. 1965); Mod. Plastics 42, No. 9. 176 (May 1965).

Substoichiometric radiometric analysis: Determination of trace amounts of cobalt, A. R. Landgrebe, L. T. McLendon, and J. R. DeVoe, Book, Radiochemical Methods of Analysis, II, 321-333 (Intern. Atomic Energy Agency, Vienna, Austria, 1965).

The constitution of $\mathrm{CuFe}_{5} \mathrm{O}_{8}$, C. F. Jefferson, J. Appl. Phys. 36, No. 3, 1165-1166 (Mar. 1965).

The gas-phase photolysis of cyclohexane in the far ultra-violet: Modes of decomposition of the neutral excited cyclohexane molecule and reactions of the parent cyclohexane ion. R. D. Doepker and P. Ausloos, J. Chem. Phys. 42, No. 11, 3746 (June 1, 1965).

The place of radiochemical methods of analysis: Today and tomor row, W. W. Meinke, (Proc. Intern. Atomic Energy Agency Symp. Radiochemical Methods of Analysis, Salzburg, Austria, Oct. 19-23, 1964). Book. Radiochemical Methods of Analysis I, 13-19 (Intern. Atomic Energy Agency, Vienna, Austria, 1965).

The vibrational assignment of sulfuryl fluoride, D. R. Lide, D. E. Mann, and J. J. Comeford, Spectrochim. Acta. 21, 497 (1965). Vacuum-ultraviolet photolysis of ethane at high tempereture, R. F Hampson, Jr., and J. R. MeNesby, J. Chem. Phys. 42, No. 6 , 2200-2208 (Mar. 15, 1965).

A comparison of atomic frequency standards, R. E. Beehler and R. C. Mockler, Book, Progress in Radio Science 1960-1963, Vol. I, Radio Standards and Measurements, pp. 20-26 (Elsevier Publ. Co., Amsterdam, The Netherlands, 1965).

A DC-RF substitution error in dual element bolometer mounts, G. F. Engen, IEEE Trans. Instr. Meas. IM-13, No. 2 \& 3, 58-64 (June-Sept. 1964).

A mechanistic model for the limits of auditory perception, E. L. R. Corliss, Proc. Symp. Models for the Perception of Speech and Visual Form, Boston, Mass., Nov. 11-14, 1964 (Air Force Research Center, Cambridge, Mass., 1964).

A multistub coaxial line tuner, W. E. Little and E. Niesen, IEEE Trans. Microwave Theory Tech. MTT-12, No. 5, 570-571 (Sept. 1964).

A survey of research on frozen food transport refrigeration, P. R. Achenbach, ASHRAE J. 6, No. 11, 29-36 (Nov. 1964).

A two-channel nulling method for measuring attenuation constants of short sections of waveguide and the losses in waveguide joints, R. W. Beatty, Proc. IEEE 53, No. 6, 642-643 (June 1965).

Advances in electrical instrumentation, F. L. Hermach, Ind. Res. pp. 60-66 (June 1965).

An automatic method for obtaining data in the Weissfloch-Feenberg node-shift technique, R. W. Beatty, Proc. IEEE 53, No. 1, 79-80 (Jan. 1965).

An unimodulated twin channel microwave attenuation measurement system, D. H. Russell, ISA Trans. 4, 162-169 (Apr. 1965).

Breakdown characteristics of semi-conductor materials, H. A. Schafft, Electro-Technol. 75, No. 6, 77-82 (June 1965).

Code for electricity metering, revised, F. K. Harris, Mag. Std. 36 , No. 5, 143-145 (May 1965).

Color filter nomograph, C. S. McCamy, Am. Cinematographer 46, No. 5, 314-315 (May 1965). 
Comments of surface characterization of real metals, D. P. DeWitt, (Symp. Thermal Radiation of Solids, San Francisco, Calif., Mar. 4-5, 1964), NASA SP-55, Session II, Paper 12, 141-144 (1965).

Comparison of single-point and two-point loading for determining the strength of flat glass, J. J. Kerper and T. G. Scuderi, Proc. Am. Soc. Testing Materials 64, 1037-1043 (1964).

Composites in construction, A. A. Bates, Stanton Walker Lecture Series on the Materials Sciences, Nov. 20, 1963, Lecture No. 1, p. 15 (University of Maryland, College Park, Md., 1964).

Computer control of precision instrument inventory, S. N. Alexander and P. E. Doyle, Research/Development pp. 38-43 (May 1965).

Correlation and prediction of thermal conductivity of metals through the application of the principle of corresponding states, A. Cezairliyan and Y. S. Touloukian, Proc. Advances in Thermophysical Properties at Extreme Temperatures and Pressures, Purdue Univ., Lafayette, Ind. Mar. 1965, pp. 301-313 (American Society of Mechanical Engineers, New York, N.Y., 1965).

Current programs in the U.S. Department of Commerce for advancing state science and technology, W. C. Bandy (Proc. 11th Annual Meeting, Denver, Colo., Oct. 19-20, 1964), Mid-Continent Research and Development Council Report, pp. 70-76 (1965).

Design of static elastomeric seals for cryogenic temperatures, D. H. Weitzel, P. R. Ludtke, and R. F. Robbins, Proc. Conf. Design of Leak-tight Separable Fluid Containers 2, 139-165 (NASA, Huntsville, Ala., Mar. 1964).

Effect of surface texture on diffuse spectral reflectance, Part A Diffuse spectral reflectance of metal surfaces, H. J. Keegan, J. C. Schleter, and V. R. Weidner, (Symp. Measurement of Thermal Radiation of Solids, San Francisco. Calif., Mar. 4-6, 1964). NASA SP-55, Session II, Paper 17, pp. 165-169 (1965).

Effects of connectors and adapters on accurate attenuation measurements at microwave frequencies, R. W. Beatty, IEEE Trans, Instr. Meas. IM-13, No. 4, 272-284 (Dec. 1964).

Experimental fires in enclosures, A. F. Robertson, 10th Symp. (Intern.) on Combustion, Cambridge, England, Aug. 1964, pp. 931-942 (1965).

Fire endurance of small gypsum slabs, J. V. Ryan, (Proc. American Society for Testing Materials Annual Meeting on Moisture Influence on Material Behavior During Fire Test, Chicago, Ill., June 1964), Am. Soc. Testing Materials Spec. Tech. Publ. No. 385, pp. 96-111 (May 1965).

Flexural behavior of prestressed split-beam composite concrete sections, J. O. Bryson, L. F. Skoda, and D. Watstein, J. Prestressed Concrete Inst. 10, No. 3, 77-91 (June 1965).

Flow field in a swirl chamber, D. H. Tsai, AIAA J. Tech. Notes 2, No. 8, 1504-1505 (Aug. 1964).

Fracture topography, I. Wolock and S. B. Newman, Book, Fracture Processes in Polymer Solids, Phenomena and Theory, ed. B. Rosen, ch. IIC, pp. 235-290 (Interscience Publ. Inc., New York, N.Y., 1964).

Further analysis of the modulated subcarrier technique of attenuation measurement, W. E. Little, IEEE Trans. Instr. Meas. IM-13, No. 2 \& 3, 71-76 (June-Sept. 1964).

High temperature seal of sapphire windows to ceramics, G. A. Horn beck, Rev. Sci. Instr. 36, No. 6, p. 845 (June 1965).

Importance of surface films, J. C. Richmond (Symp. Thermal Radia tion of Solids, San Francisco, Calif., Mar. 4-5, 1964), NASA SP-55, Session II, Paper 15, pp. 157-158 (1965).

International intercomparison of standards and microwave power measurements, G. F. Engen (Proc. 3d Intern. Measurement Conference, Stockholm, Sweden,-1964), Acta Imeko 1, 337-346 (1964).

Measuring impedance through an adapter without introducing additional error, R. W. Beatty, Proc. IEEE 53, No. 6, 656-657 (June 1965).

Method and equipment for measuring thermal emittance of ceramic oxides from $1200^{\circ}$ to $1800{ }^{\circ}$ K. H. E. Clark and D. G. Moore (Symp. Thermal Radiation of Solids, San Francisco, Calif., Mar. 4-5. 1964), NASA SP-55, Session III, Paper 26, pp. 241-257 (1965).

Microwave and high frequency calibration of the National Bureau of Standards, (Parts I-IV). R. E. Larson. IEEE Trans. Microwave Theory Tech. Part I., MTT-12, No. 4, 480-482 (July 1964); Part II, MTT-12, No. 5, 572-576 (Sept. 1964); Part III. MTT-12, No. 6, 623-624 (Nov. 1964); Part IV, MTT-13, No. 1, 138-139 (Jan. 1965).

Microwave discharge cavities operating at $2450 \mathrm{MHz}, \mathrm{F}$. C. Fehsenfeld, K. M. Evenson, and H. P. Broida, Rev. Sci. Instr. 36, 295298 (Mar. 1965).
New mode of operation of a phase sensitive detector, Y. Beers, Rev. Sci. Instr. 36, 696-700 (May 1965).

On the optimum frequency deviation in an FM system over a scatterpropagation path, H. Akima, Proc. IEEE 53, No. 2, 182-183 (Feb. 1965).

Preliminary studies directed toward determination of spectra ab sorption coefficients of homogeneous materials in the infrared at elevated temperatures, W. B. Fussell and R. Stair (Symp. Measurement of Thermal Radiation of Solids, San Francisco, Calif., Mar. 4-6, 1964), NASA SP-55, Session III, Paper 29, pp. 287292 (1965).

Progress report on aerosol packaged products, H. F. Wollin and S. Hasko, Aerosol Age Mag. 9, No. 9, 20 (Sept. 1964).

Project FIST; fault isolation by semi-automatic techniques, G. J. Rogers, Design Disclosure Workbook (Packaging), U.S. Naval Applied Science Laboratory, Brooklyn, N.Y., Draft 5 (June 1965).

Project FIST: fault isolation by semi-automatic techniques, G. Shapiro, G. J. Rogers, O. B. Laug, and P. M. Fulcomer, Jr., IEEE Spectrum. pp. 98-111 (Aug. 1964); p. 130-144 (Sept. 1964).

Radio standards and measurements, microwaves, a progress review from 1960, R. W. Beatty, Book, Progress in Radio Science. 1960-1963. Vol. I. Radio Standards and Measurements, pp. 78-81 (Elsevier Publ. Co., Amsterdam. The Netherlands, 1965). Recent developments in using elastomers for static cryogenic seals, P. R. Ludtke, Proc. Seventh National Society Aerospace Materials Process Engineers Symp.. pp. 25-1-25-14 (Western Periodicals, Los Angeles, Calif., 1964).

Sensitivity indices for Hall generators, S. Rubin. Solid State Design Mag. 5, No. 12, 38-39 (Dec. 1964).

Some factors affecting the sensitivity and spectral response of thermoelectric (radiometric) detectors, R. Stair, W. E. Schneider, W. R. Waters, and J. K. Jackson, Appl. Opt. 4, No. 6, 703-710 (June 1965).

Standard test for determining alkali resistance of porcelain enamels, M. D. Burdick. Proc. Porcelain Enamel Inst. Forum 26, 227236 (Oct. 14-16, 1964).

Standardization of definitions for Hall effect devices, S. Rubin, Proc. Rotating and Stantic Precision Components Symp.. Apr. 1964. pp. 344-360 (Bureau Naval Weapons, Washington, D.C., 1964)

Standards-still a continuing project, H. L. Mason, Control Eng. 12, No. 1, 74 (Jan. 1965).

The evolution of control system standards, H. L. Mason, 1965 Joint Automatic Control Conf., June 22-25, 1965, Session VII, Paper 1, pp. 76-78 (Renssalaer Polytechnic Inst., Troy, N.Y., 1965).

The rapid selector as currently used for information search and replica copy retrieval, T. C. Bagg. (Proc. 26th Annual Meeting of the American Documentation Institute, Chicago, Ill., Oct. 1963) Automation and Scientific Commun. Pt. 2, 227-228 (Oct. 1963).

Waveguide noise-tube mount for use in an interlaboratory noise standard, C. K. S. Miller, W. C. Daywitt, and E. Campbell, Acta. Imeko 3, 371-382 (1964).

Weather resistance of porcelain enamels exposed for seven years at various sites, M. A. Rushmer and M. D. Burdick, Proc. Porcelain Enamel Inst. Forum 26, 214-226 (Oct. 14-16, 1964).

Weight checking of aerosols, S. Hasko, Mod. Packaging Mag. 38 , No. 11, 141 (July 1965).

A new differential operator of the pure wave type, J. E. Lagnese, J. Different. Eq. 1, No. 2, 171-187 (Apr. 1965).

Aggregation in matrix models of resource flows, D. Rosenblatt, Am. Stat. 19, No. 3, 36-39 (June 1965).

An application of the inverse Z-transform theory to the synthesis of linear antenna arrays, M. T. Ma, IEEE Trans. Ant. Prop. AP-12, No. 6, 798-799 (Nov. 1964).

Analogies between theories of antenna arrays and passive networks. M. T. Ma.. IEEE Intern. Conv. Record 13, Pt. 5, 150-154 (Mar. 1965)

Application of Bernstein polynomials and interpolation theory to linear array synthesis, M. T. Ma, IEEE Trans. Ant. Prop. AP-12, 668-677 (Nov. 1964).

Mechanical translation: U.S.-Japan Joint Conference, F. L. Alt, Science 147, No. 3665, 1599-1600 (Mar. 1965).

Relation between normal trichromatic vision and dichromatic vision representing a reduced form of normal vision, D. B. Judd, Acta Chromatica 1, No. 3. 89-92 (Oct. 1964).

Some unorthodox predictions, F. L. Alt, Computers and Automation XIV. No. l, p. 11 (Jan: 1965).

The standardization of programming languages, Proc. 19th Asso- 
ciation for Computing Machinery Conf., Philadelphia, Pa.. pp B2-1 (Aug. 1964).

Training a computer to assign descriptors to documents, M. E. Stevens and G. H. Urban, Proc. Spring AFIP Joint Computer Conf., Washington, D.C., April 1964, pp. 563-575 (1964).

Use of general purpose coding systems for statical calculations, J. M. Cameron and J. Hilsenrath, Proc. IBM Scientific Computing Symp. Statistics, Thomas J. Watson Research Center, Yorktown Heights, N.Y., Oct. 21-23, 1963, pp. 281-299 (IBM, White Plains, N.Y., 1965).

You can always tell a computer but you can't tell it much, J. H. Wegstein, Proc. ARO Working Group on Computers, Harry Diamond Laboratories, Washington, D.C., Feb. 4-5, 1964, pp. 129-151 (Feb. 1965).

A system for accurate d-c and a-c voltage measurements, F. L. Hermach, J. E. Griffin, and E. S. Williams, IEEE Intern. Conv. Record 13,pt. 11, 172-182 (Mar. 1965).

An international comparison of inductive voltage divider calibrations at 400 and 1000 hertz. W. C. Sze, A. F. Dunn, and T. L. Zapf, IEEE Intern. Conv. Record 13, pt. 11, 126-135 (Mar. 1965).

APPA-TAPPI reference material program. III. A discussion of lambda variance and its application to TAPPI standard T 414 m-49 for internal tearing resistance of paper, T. W. Lashof, Tappi 47, No. 8, 445 (Aug. 1964).

Comments on Zener diodes as voltage standards, W. G. Eicke, Jr., Comite Consultatif D'Electricite 10 ${ }^{\mathrm{e}}$ Session, May 2-3, 1963 , pp. 27-30 (Gauthier-Villars, Paris, France, 1963).

Construction and behavior of a transportable ten picofarad capacitor, R. D. Cutkosky and L. H. Lee, Comite Consultatif D'Electricite $10^{\mathrm{e}}$ Session, May 2-3, 1963, p. 44-48 (Gauthier-Villars Paris, France, 1963)

Electronic $g$ factor or rubidium, R. L. Driscoll, Phys. Rev. 136, No. 1A, A54-A57 (Oct. 5, 1964).

Microwave calibration techniques at the National Bureau of Standards, R. E. Larson (Proc. Intern. Measurements Conf.), Acta Imeko 3, 383-393 (1964).

National Bureau of Standards gas thermometer. III. Constant volume valve, R. L. Anderson and L. A. Guildner, Rev. Sci. Instr. 36, No. 5, 615-616 (May 1965).

Simultaneous dielectric constant and volume measurements on liquids at high pressures, N. L. Brown, Proc. Electrical Insulation Conf., Cleveland, Ohio, Oct. 1964, Natl. Acad. Sci.-Natl. Res Council Publ. 1238, pp. 36-40 (1965).

Spacetime coordinate systems, G. E. Hudson, Proc. Intern. Conf Chronometry, pp. 197-221 (Lausanne, Switzerland, June 1964).

Standards, sources, and detectors in radiation measurements, $\mathrm{R}$ Stair and W. E. Schneider (Symp. Measurement of Thermal Radiation of Solids, San Francisco, Calif., Mar. 4-6, 1964), NASA SP55, Session III, Paper 24, pp. 217-231 (1965).

Planning for better measurement accuracy, R. D. Huntoon and W. A Wildhack, ISA J. 12, No. 1, 57-60 (Jan. 1965).

Uncertainties associated with proving ring calibration error, T. E. Hockersmith and H. H. Ku, ISA J. 12, No. 6, 73-77 (June 1965)

A dumbbell model for dielectric dispersion in paraffin-like solids, M. G. Broadhurst, Proc. Electrical Insulation Conf., Cleveland, Ohio, Oct. 1964, Natl. Acad. Sci.-Natl. Res. Council Publ. 1238, pp. 129-132 (1965)

A method for determination of the tropospheric temperature struc ture from ground-based measurement of oxygen emission, E. R. Westwater, Proc. 3d Remote Sensing of the Environment, Infrared Phys. Lab., Inst. Sci. Tech., Univ. Michigan, Ann Arbor, Mich., Feb. 1965, pp. 245-256 (Mar. 1965).

A possible mechanism for light absorption by interstellar grains, E. E. Ferguson and H. P. Broida, Astrophys. J. 141, No. 2, 807-809 (Feb. 15, 1965).

A test of analytical expressions for the thermal emittance of shallow cylindrical cavities, F. J. Kelley and D. G. Moore (Symp. Thermal Radiation of Solids, San Francisco, Calif., Mar. 4-5, 1964), NASA SP-55, Session I, Paper 10, pp. 117-121 (1965); Appl. Opt. 4, No. 1, 41-40 (1965).

A theoretical study of the Martian and Cytherian ionospheres, R. B. Norton, Natl. Aeron. Space Admin. NASA Tech. Note D-2333 (July 1964).

Albert Einstein, as I remember him, C. Eisenhart, J. Wash. Acad Sci. 54, 325-328 (Nov. 1964).

An experimental study of the backscattering of $5.3 \mathrm{meV}$ alpha particles from platinum and monel metal, D. H. Walker, Intern. J. Appl. Radiation Isotopes 16, 183-189(1965).
Annual observatory report from the National Bureau of Standards, C. E. Moore, Astron. J. 69, No. 9, 696-698 (Nov. 1964).

Beam loading in linear accelerators, J. E. Leiss, IEEE Trans. Nuclear Sci. NS-12, No. 3, 566-579 (June 1965).

Calibration of Schlieren systems, J. R. Meyer-Arendt and E. P. Shettle, J. Appl. Opt. Letter 4, No. 6, 757 (June 1965).

Characteristics of soil and vegetated surfaces to reflected and emitted radiation, D. M. Gates, Proc. 3d Symp. Remote Sensing Environment, Infrared Phys. Lab., Inst. Sci. Tech., Univ. Michigan, Ann Arbor, Mich., Feb. 1965, pp. 573-600 (Mar. 1965).

Chromatography on glass of controlled pore size, W. Haller, Nature 206, 693-696 (1965).

Compound-atom states for two-electron systems, T. F. O'Malley and S. Geltman, Phys. Rev. 137, No. 5A, A1344-A1352 (Mar. 1, 1965).

Condensation of tungsten on tungsten in atomic detail: Monte Carlo and statistical calculations vs experiment, R. D. Young and D. C. Schubert, J. Chem. Phys. 42, No. 11, 3943-3950 (June 1965).

Condensation of tungsten on tungsten in atomic detail: Observation with the field ion microscopy, P. Gurney, Jr., F. Hutchinson, and R. D. Young, J. Chem. Phys. 42, No. 11, 3939-3943 (June 1965).

Continuum states of $\mathrm{H}^{-}$and the free-free absorption coefficient, S. Geltman, Astrophys. J. 141, No. 2, 376-394 (Feb. 12, 1965).

Correction of optical distance measurements for the fluctuating atmospheric index of refraction, P. L. Bender and J. C. Owens, J. Geophys. Res. 70, No. 10, 2461-2462 (May 15, 1965).

Correlated walk and diffusion equations in a driving force, J. R. Manning, Phys. Rev. 139, No. 1A, Al26-A135 (July 5, 1965).

Coupling of particle-hole states and two particle-two hole states: damping, M. Danos and W. Greiner, Book, Physique Nucleaire, ed. P. Gugenberger, II, 615-616 (Editions due Centre National de la Recherche scientific, Paris, France, 1964).

Critical examination of vibrational energy-transfer theory, F. H. Mies, J. Chem. Phys. 42, No. 8, 2709-2720 (Apr. 15, 1965).

Crystal growth and thermal etching of argon, G. L. Pollack and E. N. Farabaugh, J. Appl. Phys. 36, 513 (1965).

Damping of the giant resonance in heavy nuclei, M. Danos and W. Greiner, Phys. Rev. 138, No. 4B, B876-B891 (May 1965).

Dissociative recombination in helium afterglows, E. E. Ferguson, F. C. Fehsenfeld, and A. L. Schmeltekopf, Phys. Rev. 138A, A381-A385 (Apr. 1965)

Dynamic collective theory of odd-A nuclei, M. Danos, W. Greiner, and C. B. Kohr, Phys. Rev. 138, No. 5B, B1055-B1066 (June 1965).

Electron accelerators for food processing, H. W. Koch and E. H. Eisenhower, Proc. Intern. Conf. Radiation Preservation of Foods, Boston, Mass., Sept. 27-30, 1964, Natl. Acad. Sci.-Natl. Res. Council Publ. 1273, pp. 149-180 (1965).

Electron spin resonance of $\mathrm{Mo}^{5+}$ in rutile, T. T. Chang, Phys. Rev. 136, No. 5A, A1413-A1416 (Nov. 30, 1964).

Empirical relations for energy levels of atoms and ions, A. E. Goertz, J. Opt. Soc. Am. 55, 742-743 (June 1965).

Energy levels of $\mathrm{Pr}^{3+}$ in the vapor state, J. Sugar, Phys. Rev. Letters 14, No. 18, 731-732 (May 3, 1965).

Energy levels of polarons in a magnetic field, D. M. Larsen, Phys. Rev. 135, No. 2A, A419-A426 (July 1964).

Energy of the formation of the anion Frenkel pair in calcium fluoride A. D. Franklin, J. Phys. Chem. Solids 26, 933-934 (1965).

Etch pits in chromic oxide, W. S. Brower, Jr., and E. N. Farabaugh, J. Appl. Phys. 36, No. 4, 1489-1490 (Apr. 1965).

Excitation of molecular rotation by slow electrons, K. Takayanagi and S. Geltman, Physics Letters 13, No. 2, 135-137 (Nov. 15 , 1964): Phys. Rev. 138, No. 4A, A1003-A1010 (May 17, 1965).

Expertise or experiments, C. Eisenhart, Science 146, No. 3647, 997-998 (Nov. 20, 1964).

$4 \mathrm{fnl}$ configurations of doubly ionized cerium (Ce III), N. Spector, J. Opt. Soc. Am. 55, No. 5, 492-501 (May 1965).

$\Gamma_{0}$ selection rules in $\mathrm{Su}(12) \bar{p} p$ annihilation, H. Harari, H. J. Lipkin, and S. Meshkov, Phys. Rev. Letters 20, No. 14, 845-847 (May 17, 1965).

Generalized master equation for quantum mechanical systems to all orders in the density, J. Weinstock. Phys. Rev. 136, 2d series, No. 4A, A879-A888 (Nov. 1964).

High energy x-ray photon albedo, J. S. Pruitt, Nuclear Instr. Methods 27, 23 (1964).

High voltage Laue x-ray photography of large single crystals, B. Paretzkin and H. S. Peiser, Science 146, 260 (1964). 
Higher-order skewnesses in a turbulent field, F. N. Frenkiel and P. S. Klebanoff, Compt. Rend. 260, 6026-6029 (1965).

Hyperfine structure of $\mathrm{Hg}^{193 *}$. $\mathrm{Hg}^{195 *}$ by Zeeman level crossings, W. W. Smith, Phys. Rev. 137, No. 2. 580-591 (Jan. 1965).

Interaction potential between $\mathrm{He}$ and $\mathrm{H}_{2}$, M. Krauss and F. H. Mies, J. Chem. Phys. 42, No. 8, 2703-2708 (Apr. 15, 1965).

International comparison of atomic frequency standards via VLF radio signals, A. H. Morgan, B. E. Blair, and E. L. Crow, Book, Progress in Radio Science, Vol. I. Radio Standards and Measurement, p. 40 (Elsevier Publ. Co., Amsterdam, The Netherlands, 1965).

Isotropic determination of the vibrational numbering for the $\mathrm{B}^{3} \mathrm{II}_{0}+u$, R. L. Brown and T. C. James, J. Chem. Phys. 42, No. 1, 33-35 (Jan. 1965).

Laser double-quantum photodetachment of $\mathrm{I}^{-}$, J. L. Hall, E. J. Robinson, and L. M. Branscomb, Phys. Rev. Letters 14, No. 25, 1013-1016 (June 21, 1965).

Loop prominences and coronal condensations. I. Non-thermal velocities within loop prominences, J. T. Jefferies and F. Q. Orrall, Astrophys. J. 141, No. 2, 505-518 (Feb. 15, 1965).

Loop prominences and coronal condensations. II. The sources of mass and energy and a model of the loop prominence mechanism, J. T. Jefferies and F. Q. Orrall, Astrophys. J. 141, No. 2, 519-525 (Feb. 15, 1965).

Low $-Z$ dye systems for ionizing radiation measurement, W. L. McLaughlin and L. Chalkley, J. Photo. Sci. Engr. 9, No. 3, 159-166 (May-June 1965).

Master equations and Markov processes, I. Oppenheim and K. E. Shuler, Phys. Rev. 138, No. 4B, B1007-B1011 (May 24, 1965).

Matrix-isolation study of the reaction of $\mathrm{F}$ atoms with CO. Infrared and ultraviolet spectra of the free radical FCO, D. E. Milligan, M. E. Jacox, A. B. Bass, J. J. Comeford, and D. E. Mann, J. Chem. Phys. 42, No. 9, 3187-3195 (May 1965).

Measurements of the viscosity of parahydrogen, D. E. Diller, J. Chem. Phys. 42, No. 6, 2089-2100 (Mar. 1965).

Microscopic-astrophysics and the development of astrophysicallaboratories, R. N. Thomas, Bull. Assoc. Devel. Intern. Observatoire de Nice, No. 1, pp. 7-16 (1964).

Microscopic fluctuations and diffusion coefficients of a non-equilibrium plasma in a magnetic field, J. Weinstock, Phys. Fluids 8 , No. 3, 479-481 (Mar. 1965).

Mobilities and reaction rates of ions in helium, E. C. Beaty and P. L. Patterson, Phys. Rev. 137, No. 2A, A346-A357 (Jan. 1965).

Multipole matrix elements of the translation operator, M. Danos and L. C. Maximon, J. Math. Phys. 6, 766 (1965).

New odd levels of neutral erbium (Er I), N. Spector, J. Opt. Soc. Am. 55, No. 5, 576-577 (May 1965).

New Rydberg series in molecular oxygen near $500^{\circ} \mathrm{A}$, K. Codling and R. P. Madden, J. Chem. Phys. 42, No. 11, 3935-3938 (June 1965).

Non-equilibrium thermodynamics of canonically invariant relaxation processes, H. C. Andersen, I. Oppenheim, K. E. Schuler, and G. H. Weiss, J. Chem. Phys. 41, No. 10, 3012-3019 (Nov. 1964).

Non-equilibrium thermodynamics of creep in polycrystals, R. E. Nettleton, Physica 20, 1989-2002 (1964).

Note on the theory of cavity ionization chambers, L. V. Spencer, Radiation Res. 25, No. 2, 352-358 (June 1965).

Nuclear magnetic resonance in $\mathrm{RbMnF}_{3}$, R. E. Payne, R. A. Forman, and A. H. Kahn. J. Chem. Phys. 42, No. 11, 3806-3808 (June 1965).

Nucleate boiling of hydrogen, D. E. Drayer, Ind. Eng. Chem. Fundamentals 4, No. 2, 167-171 (May 1965).

Observations of carbon monoxide and oxygen on tantalum with the field emission microscope, R. Klein, J. Chem. Phys. 41, No. 2, 571 (July 1964).

Observations of dislocation sources in stainless steel, A. W. Ruff, Jr., and H. G. F. Wilsdorf, Acta Met. 13, No. 6, 694-695 (1965).

On the identification of energy levels of negative ions, U. Fano and J. W. Cooper, Phys. Rev. 138, No 2A, A400-A402 (Apr. 1965).

On the nature of plasma resonance, W. M. Leavens, Physics Letters 15, No. 4, 310-311 (Apr. 1965).

Optical constants of iron in the visible region. H. T. Yolken and J. Kruger, J. Opt. Soc. Am. 55, No. 7, 842-844 (July 1965).

Optical depolarization and scintillation measurements over a terrestrial path. J. R. Meyer-Arendt, Proc. 3d Tropospheric Refraction Effects Meeting 1, 115-123 (Nov. 1964).

Optical detection of microwave transitions between excited electronic state of $\mathrm{CN}$ and the identification of the transitions in- volved, K. M. Evenson, J. L. Dunn, and H. P. Broida, Phys. Rev. 136, No. 6A, A1566-A1571 (Dec. 14, 1965).

Optical radar using a corner reflector on the moon, C. O. Alley, P. L. Bender, R. H. Dicke, J. E. Faller, P. Franken, H. H. Plotkin, and D. T. Wilkinson, J. Geophys. Res. 70, No. 9, 2267-2269 (May 1, 1965).

Optimization of the Czerny-Turner spectrometer, A. B. Shafer, L. R. Megill, and L. A. Droppleman, J. Opt. Soc. Am. 54, No. 7, 879887 (July 1964.

Photonuclear reactions, E. Hayward, Book, Nuclear Structure and Electromagnetic Transitions, ed. N. MacDonald, p. 141 (Oliver and Boyd, Edinburgh and London, England, 1965).

Possible implications of the observed profile of $(\lambda$ 6374) FeX, C. Pecker-Wimel and R. N. Thomas, Astrophys. J. 141, No. 2 , 834-836 (Feb. 15, 1965).

Potential distribution in a rectangular semiconductor bar for use with four-point probe measurements, M. J. Reber, Solid State Electron. 7, No. 7, 525-529 (July 1964).

Rearrangement kinetics of the liquid-liquid immiscible microphases in alkali borosilicate melts, W. Haller, J. Chem. Phys. 42, 686693 (1965).

Report of subcommittee D-atomic spectra, C. E. Moore, J. Opt. Soc. Am. Tech. Notes 55, No. 6, 745 (1965).

Report of the acoustics research survey committee, R. K. Cook and G. W. Wood, J. Acoust. Soc. Am. 37, No. 2, 392-395 (Feb. 1965).

Shell model treatment of nuclear reactions, M. Danos and W. Greiner. Phys. Rev. 138, No. 1B, B93-B103 (Apr. 1965).

Shift of the $R(0)$ and $P(1)$ infrared lines of $\mathrm{HCl}$ perturbed by noble gases, A. Ben-Reuven, J: Chem. Phys. 42, No. 6, 2037-2042 (Mar. 15, 1965).

Some considerations relative to an atomic definition for the unit of time, R. C. Mockler and J. M. Richardson, Proc. Consultative Committee for the Definition of the Second of the International Committee of Weights and Measures, Paris, France, Apr. 1961, pp. 58-65 (Dec. 1964).

Some measured rates for oxygen and nitrogen ion-molecule reactions of atmospheric inportance, including $\mathrm{O}^{+}+\mathrm{N}_{2} \rightarrow \mathrm{NO}^{+}+\mathrm{N}, \mathrm{F}$. C. Fehsenfeld, A. L. Schmeltekopf, and E. E. Ferguson, Planetary Space Sci. 13,219-223 (Mar. 1965).

Spin-orbit coupling constant of nitric oxide. Determination from fundamental satellite band origins, T. C. James and R. J. Thibault, J. Chem. Phys. 41, No. 9, 2806-2813 (Nov. 1964).

Surface ionization of niobium, M. D. Scheer and J. Fine, J. Chem. Phys. 42, 3645 (1965).

Tables of dielectric constants, dipole moments and dielectric relaxation times, F. I. Mopsik, 1963 Digest of Literature on Dielectrics Publ. 1230, 27, 23-55 (1964).

Tables of thermodynamic properties of air in chemical equilibrium including second virial corrections from $1500{ }^{\circ} \mathrm{K}$ to $15,000{ }^{\circ} \mathrm{K}, \mathrm{J}$ Hilsenrath and M. Klein, Arnold Eng. Develop. Center, Air Force Systems Command, AEDC-TR-65-58 (Arnold Air Force Station, Tenn., Mar. 1965).

The effect of moisture on surface flammability of coated and uncoated cellulosic materials, T. G. Lee, J. L. Loftus, and D. Gross, Am. Soc. Testing Materials Spec. Tech. Publ. 385, 112-123 (May 1965).

Total photonuclear cross sections for low atomic number elements, J. M. Wyckoff, H. W. Koch, B. Ziegler, and R. Uhlig, Phys. Rev. 137, No. 3B, B576-B594 (Feb. 1965).

Wave mode modification in liquid helium with clamped normal fluid, G. L. Pollack and J. R. Pellam, Proc. 9th Intern. Conf. Low Temperature Physics, Columbus, Ohio, Sept. 1964, p. 166 (Plenum Press Inc., New York, N.Y., 1965).

Width of the microwave lines of oxygen and their relationship to the thermal noise emission spectrum of the atmosphere, R. L. Abbott, Proc. 3d Symp. Remote Sensing of the Environment, Infrared Phys. Lab., Inst. Sci. Tech. Univ., Michigan, Ann Arbor, Mich., Feb. 1965, pp. 257-269 (Mar. 1965).

Widths of transmission Kikuchi lines in silicon and diamond, H. A. Fowler and L. Marton, J. Appl. Phys. 36, No. 6, 1986-1995 (June 1965).

W-spin analysis of weak decays in U(12) D. Horn, M. Kugler, H. J. Lipkin, S. Meshkov, J. C. Carter, and J. J. Coyne, Phys. Rev. Letters 14, No. 17, 717-719 (Apr. 1965).

W-spin and B-spin subgroups of SU(12), H. J. Lipkin and S. Meshkov, Phys. Rev. Letters 16, No. 14, 670-672 (Apr. 19, 1965). 
A comparison of mountain slope and radiosonde observations, C. A. Sampson, Mo. Weather Rev. 93, No. 5, 327-330 (May 1965).

A study of auroral absorption events at the South Pole: I. Characteristics of the events, J. K. Hargreaves, H. J. A. Chivers, and J. D. Petlock, J. Geophys. Res. 69, No. 23, 5001-5007 (Dec. 1964).

Attenuation of radio waves in the troposphere, B. R. Bean, Book, Advances in Radio Research 1, 121-155 (Academic Press Inc., New York, N.Y., 1964).

ESD Maui, Hawaii, measurements, M. C. Thompson, Jr., Proc. 3d Tropospheric Refraction Effects Meeting 1, 89-93 (Nov. 1964).

Fading on microwave line-of-sight paths, H. T. Dougherty, Proc. 3d Tropospheric Refraction effects Meeting 1, 125-135 (Nov. 1964).

Formation of an electron depleted region in the ionosphere by chemical releases, J. W. Wright, D. Golomb, N. W. Rosenberg, and J. A Barnes, (Proc. 4th Intern. Space Science Symp., Warsaw, Poland, June 4-10, 1963), Space Res. IV, 389-398 (North-Holland Publ. Co., Amsterdam, The Netherlands, 1964).

Ionosphere explorer I satellite: first ovservations from the fixedfrequency topside sounder, W. Calvert, K. W. Knecht, and T. E. VanZandt, Science 146, No. 3642, 391-395 (Oct. 16, 1964).

Ionospheric effects observed around the time of the Alaskan earthquake of March 28, 1964, K. Davies and D. M. Baker, J. Geophys. Res. 70, No. 9, 2251-2253 (May 1, 1965).

Ionospheric propagation on high frequencies, K. Davies, 4U11TU Calling 2, 112-113 (1965).

Noise tests of an airborne microwave refractometer system, M. C. Thompson, Jr., and W. B. Grant, Rev. Sci. Instr. 36, No. 6 , 758-759 (June 1965).
Prediction of ionospheric characteristics at CRPL for sky-wave radio propagation at high frequencies, K. Davies, Telecommun. J. 31, No. 12, 339-350 (Dec. 1964).

Radiation efficiencies of half-wave dipole antennas, R. G. FitzGerrell, IEEE Trans. Ant. Prop. AP-13, 326-327 (Mar. 1964).

Radio astronomy observations with the $8.4 \times 10^{4} \mathrm{~m}^{2} 50 \mathrm{Mc} / \mathrm{s}$ antenna of the Jicamarca radar in Peru, W. K. Klemperer and G. R. Ochs, Astron. J. 70, No. 1327, 141-142 (Mar. 1964).

Receiver noise factor, E. Hildner, Proc. Intern. Telemetry Conf., Washington, D.C., May 16-20 1964, pp. 326-333 (May 1965).

The contribution of non-thermal electrons to auroral absorption of radio waves, G. C. Reid, J. Geophys. Res. 69, No. 15, 32963298 (Aug. 1964).

The daytime equatorial $F$-layer, R. B. Norton and T. E. VanZandt, J. Atmospheric and Terrest. Phys. 26, 1047-1054 (1964).

The distribution of electrons in the lower and middle ionosphere, R. W. Knecht, Book, Progress in Radio Science 1960-1963, Vol. III. The Ionosphere, pp. 14-45 (Elsevier Publ. Co., Amsterdam, The Netherlands, 1965).

The light of the night sky: astronomical interplanetary and geophysical, F. E. Roach, Space Sci. Rev. 3, 512-540 (Nov. 1964).

*Publications for which a price is indicated are available by purchase from the Superintendent of Documents, U.S. Government Printing Office, Washington, D.C., 20402 (foreign postage, one-fourth additional). Reprints from outside journals and the NBS Journal of Research may often be obtained directly from the authors. 